International Journal of Climatology

February 2017, Volume 37, Issue 2, Pages 870-889

http://dx.doi.org/10.1002/joc.4746

http://archimer.ifremer.fr/doc/00334/44536/

(c) 2016 Royal Meteorological Society

\title{
Homogenization of scatterometer wind retrievals
}

\author{
Bentamy Abderrahim ${ }^{1,{ }^{*}}$, Grodsky Semyon A. ${ }^{2}$, Elyouncha Anis ${ }^{3}$, Chapron Bertrand ${ }^{1}$, \\ Desbiolles Fabien ${ }^{1,4}$
}

${ }^{1}$ Laboratoire d'Océanographie Spatiale; Institut Francais pour la Recherche et l'Exploitation de la Mer; Plouzané France

${ }^{2}$ Department of Atmospheric and Oceanic Science; University of Maryland; College Park MD USA

${ }^{3}$ Department of Communication, Information, Systems \& Sensors; Royal Military Academy; Brussels

Belgium

${ }^{4}$ Laboratoire d'Océanographie Physique (LPO); Université de Bretagne Ouest (UBO); Brest France

* Corresponding author : Abderrahim Bentamy, email address : Abderrahim.Bentamy@ifremer.fr

\begin{abstract}
:
Surface winds ( $10 \mathrm{~m}$ equivalent neutral wind velocity) from scatterometer missions since 1992 to present require homogenization to meet the requirements for oceanic and atmospheric climate data records. Sources of differences between winds retrieved from different scatterometer measurements mainly arise from calibration/validation procedures used for each scatterometer and differences in measurement physics. In this study, we focus on the calibration/validation component of the European Remote Sensing Satellite (ERS)-1 and ERS-2 wind speed biases. ERS-1 and ERS-2 data, named as WNF products, are from the Institut Français de Recherche pour l'Exploitation de la MER (IFREMER). In addition to WNF data, the newly calibrated ERS-2 products provided by the European Space Agency (ESA), indicated as ASPS2.0 products, are also used. Our approach utilizes collocated satellite-buoy data. Expected values of the normalized radar cross section (NRCS) are calculated from buoy winds for each antenna beam using the Cmod5.n geophysical model function. The comparisons between expected and measured NRCS examine differences along with variables such as backscatter coefficient and incidence angle ranges. The difference between the expected and measured NRCS is then used to set up empirical models aiming at the correction for biases in ERS-1 and ERS-2 WNF NRCS calibrations. Finally, ERS-1 and ERS-2 wind retrievals are reprocessed using the corrected NRCS and Cmod5.n. These earlier corrected ERS-1/2 winds are analysed along with later scatterometer data (QuikSCAT and ASCAT-A) for their deviations from in situ buoy winds during 1992-2011 period. The scatterometer data homogeneity is also investigated at global scales based on the use of collocated scatterometer retrievals and atmospheric re-analyses winds derived from ERA Interim and CFSR models.
\end{abstract}

Keywords : scatterometer, surface wind, homogenization 


\section{Introduction}

Surface wind vectors are vital for operational and scientific issues. For instance, they are routinely used as primary forcing function component for ocean circulation and wave models at global and/or local scales. They are considered as the most important variable for investigating storm surges and wave forecasts at various space and time scales. They have great impact on coastal upwelling, primary productivity, cross shelf transport, deep water formation, ice transport and variability. They are essential for reliable estimation of momentum (wind stress vector), heat fluxes (latent and sensible), and gas fluxes (e.g. $\mathrm{CO}_{2}$ and $\mathrm{H}_{2} \mathrm{O}$ ). Long term change in global winds is an important forcing and indicator of the climate change (e.g. Bourassa et al, 2010). .

One of the main sources of surface wind speed and direction over the global ocean are scatterometers on board polar satellites. Since the launch of the European Remote Sensing Satellite (ERS-1) in August 1991, a total of 10 independent scatterometer missions have been operational. The European Space Agency (ESA) operated two scatterometers onboard the European Remote Sensing Satellites ERS-1 (1991 - 1996) and ERS-2 (1995 - 2011). Three scatterometers have been operated by the National Aeronautic Space Administration (NASA): NASA scatterometer (NSCAT, 1996 - 1997) onboard the Japanese Advanced Earth Observing Satellite (ADEOS-1), SeaWinds onboard QuikSCAT satellite (1999 - 2009), and SeaWinds onboard (ADEOS-2/Midori) (2002 - 2003). The latest scatterometers are the Advanced SCATterometer ASCAT-A (2006 - present) and ASCAT-B (2013 - present) onboard METOP satellites, Ocean SCATterometer (OSCAT) onboard OCEANSAT2 satellite (2009 - present), and HY-2A scatterometer (2011 - present). ASCAT-A/B, OSCAT, and HY-2A, and RapidScat are operated by European Meteorological Satellite organization (EUMETSAT), Indian Space Research Organization (ISRO), the Chinese National Space Center (CAS), and by NASA, respectively. Thanks to the overlapping periods between missions, scatterometer winds are continuously available over global ocean and span more than two decades (1992 - present). The quality of each scatterometer retrievals have been investigated by a number of authors (e.g. Quilfen, 1995; Graber et al 1996; Freilich and Dunbar, 1999, Bentamy et al, 2002; Ebuchi et al, 2002; Bentamy et al, 2008; Verspeek et al, 2010; Sudha and Rao, 2013). They found that remotely sensed winds are comparable to in situ measurements (mainly from moored buoys). Furthermore, scatterometer products relied on each mission have been successfully used for numerous purposes such as ocean model forcing experiments (e.g. Grima et al, 1999; Ayina et al, 2006), extreme event studies (e.g. Le Marchal et al, 2000; 
1 Katsaros et al, 2001), and upwelling space and time patterns (Blanke et al, 2005; Penven et al, 2 2005).

3 The main weakness of using scatterometer data for a long term wind analysis is the lack

4 of consistency between retrievals from different scatterometers. Bentamy et al $(2012,2013)$ 5 have highlighted the differences between surface winds retrieved from ASCAT-A and 6 QuikSCAT, and between ERS-2 and QuikSCAT. Differences in wind retrievals originate from differences in radar physics and procedures used to retrieve near surface winds from measured backscatter coefficients. In the two above papers, a chain of corrections has been applied to individual mission winds to improve the consistency between ERS-2, QuikSCAT, and ASCAT-A. Application of those corrections reduces the global mean of intermission wind difference as well as reduces the magnitude of its geographical patterns.

This study considers four scatterometer missions (ERS-1, ERS-2, QuikSCAT, and ASCAT) spanning two decades from 1992 through 2011. Comparisons of each mission winds with collocated in situ winds from ocean buoys reveal stronger deviations for both ERS missions. Calibration of normalized radar backscatter $\left(\sigma^{0}, \mathrm{NRCS}\right)$ is revisited for ERS-1 and ERS-2 by comparing expected NRCS (calculated from collocated buoy winds using the Cmod5.n Geophysical Model Function, GMF) with measured NRCS. The difference between the expected and measured $\sigma^{0}$ is then used to correct biases in measured NRCS. Finally, ERS-1 and ERS-2 winds are reprocessed using the corrected $\sigma^{0}$ and Cmod5.n. Resulting winds from the four scatterometers are analyzed for their inter mission deviations and consistency with buoy winds during $1992-2011$

\section{Data}

\subsection{Scatterometer data}

For more than two decades, a sequence of scatterometers onboard polar satellites has been providing unique observations of winds over the global ocean. Continuous surface wind records are available from ten missions spanning late 1991 through present. These missions include C-band (5.3 GHz) scatterometers onboard ERS-1, ERS-2 and METOP-A(ASCAT), and higher frequency Ku-band (13.4 GHz) SeaWinds onboard QuikSCAT (indicated as QSCAT hereafter)

Scatterometers are microwave radars that infer near-surface wind velocity from NRCS,

$31\left(\sigma^{0}\right)$ measured at a variety of azimuth $(\chi)$ and incidence angles $(\theta)$. The ocean surface radar 32 backscatter occurs primarily from centimeter-scale capillary/gravity waves (ripples), whose 
1 amplitude is in equilibrium with the local near-surface wind. Measurements of NRCS are used to estimate equivalent neutral wind (ENW) speed $(W)$ and direction $(\varphi)$ at $10 \mathrm{~m}$ height Equivalent neutral wind is the wind speed that would be associated with the actual wind stress if the atmospheric boundary layer was neutrally stratified. $W$ and $\varphi$ are related to $\sigma^{0}$ through the Geophysical Model Function (GMF). The latter is a nonlinear function involving $\theta$ and $\chi$ dependency (e.g. Bentamy et al, 1999; Wentz and Smith, 1999; Hersbach, 2010). Wind retrievals are available at Wind Vector Cell (WVC) along scatterometer swath. Spatial resolution varies between $12.5 \mathrm{~km}^{2}$ and $50 \mathrm{~km}^{2}$ for different scatterometer products.

In this study we consider the swath data (level 2, L2b) from ERS-1, ERS-2, QSCAT, and ASCAT-A (hereafter ASCAT). Table 1 provides particular characteristics of each scatterometer including its operating period, repeat cycle, radar frequency/wavelength, GMF used for wind retrieval processing, the version of L2b product used in this study, , and WVC spatial resolution. The agencies processing and distributing these data (shown in the last column of Table 1) are Institut Français pour la Recherche et l'Exploitation de la MER (IFREMER), European Space Agency (ESA), NASA Jet Propulsion Laboratory (JPL), and European Meteorological Satellite (EUMETSAT).

Original data listed in Table 1 have been corrected (except ERS-2 ASPS2.0, assumed well calibrated) to decrease inter-mission biases. In particular, the original QSCAT winds distributed by NASA/JPL have been corrected for a SST-related bias. This correction depends on wind speed and the sea surface temperature (SST) and accounts for stronger viscous dissipation (especially noticeable at cold $\mathrm{SST}<5^{\circ} \mathrm{C}$ ) of Bragg waves in $\mathrm{Ku}$-band in comparison with C-band (Bentamy et al, 2011; Grodsky et al, 2012, Bentamy et al., 2013). This new QSCAT wind is referred to as QSCAT/N. It also employs an enhanced rain filtering based on the regular rain flag along with the multidimensional rain probability, which must be $<0.05$ for rain free data (Bentamy et al, 2011).

ASCAT winds have been also modified from their original version distributed by the EUMETSAT. These modified winds are referred to as ASCAT/N. They are corrected for GMF-related bias, which has been parameterized in Bentamy et al. (2011) as a function of ASCAT wind speed and direction relative to the mid-beam azimuth.

Scatterometers onboard ERS-1 and ERS-2 are identical in design. Both are C-band radars that have three antennae looking $45^{\circ}$ forward (fore-beam), perpendicular (mid-beam), and $45^{\circ}$ backward (aft-beam) relative to the satellite track and illuminating a 500km wide swath to the right of the satellite track. Fore-beam and aft-beam incidence angles vary from 
$124^{\circ}$ (inner swath) to $57^{\circ}$ (outer swath), whereas mid-beam incidence angles vary from $18^{\circ}$ to $246^{\circ}$.

ERS-1 and ERS-2 winds are inferred at $50 \mathrm{~km}^{2}$ spatial resolution using IFREMER version 2 GMF (CMODIFR2 of Bentamy et al., 1999). CMODIFR2 was derived by fitting ERS-1 winds to collocated National Data Buoy Center (NDBC) buoy winds. CMODIFR2 has been applied to ERS-2 without any further adjustments. These ERS-1 and ERS-2 datasets including their corresponding NRCS values are distributed by IFREMER and indicated as WNF products. Land, ice, and rain contaminations are excluded using quality flags included into WNF products.

Previous studies have found that ERS-2 WNF wind speed is underestimated versus buoy and QSCAT/N winds (e.g. Bentamy et al, 2002; Bentamy et al., 2013). This ERS-2 wind bias is related to biases in radar calibration and GMF. In fact, the bias versus QSCAT/N is apparently reduced if Cmod5.n GMF is applied instead of CMODIFR2 (Bentamy et al., 2013). Recently the Advanced Scatterometer Processing System (ASPS) project run by ESA in collaboration with the Royal Military Academy (RMA) of Belgium has addressed the interbeam calibration issue by recalibrating ERS-2 $\sigma^{0}$ measurements over quasi-homogeneous tropical rainforests targets. Reprocessed ERS-2 winds (referred to as UWI) are based on Cmod5.n GMF and available globally from June 1997 through January 2001 at nominal $50 \mathrm{~km}^{2}$ and $25 \mathrm{~km}^{2}$ spatial resolutions (De Chiara et al, 2009; Crapolicchi et al, 2012). Only high resolution data are used in this study. But, the UWI reprocessing are only available from the middle of 1997 only, thus does not overlap with ERS-1.

\subsection{Buoy data}

The ground truth surface wind speed and direction and accompanying oceanic and atmospheric parameters are obtained from moored buoys. Two buoy networks are used in this study. The first network is maintained by the National Data Buoy Center (NDBC). NDBC buoys are moored off US coasts spanning middle latitude range from $20^{\circ} \mathrm{N}$ to $65^{\circ} \mathrm{N}$. The second network operates in the tropics and includes Tropical Atmosphere Ocean (TAO), Prediction and the Research Moored Array in the Atlantic (PIRATA), and the Research Moored Array for African-Asian-Australian Monsoon Analysis and Prediction (RAMA) 30 buoys. TAO, PIRATA, and RAMA are moored in the tropical Pacific, Atlantic, and Indian, respectively and are referred to as tropical buoys (www.pmel.noaa.gov/tao/). To provide compatibility with scatterometer winds, the buoy measurements are transformed into ENW at standard 10m height using the COARE3.0 algorithm of Fairall et al. (2003). This algorithm 
1 requires the knowledge of sea surface temperature (SST), air temperature (Ta), and relative 2 humidity ( $\mathrm{Rh}$ ) (or related variables). All these parameters are available from the tropical

\subsection{Numerical Weather Prediction (NWP) data}

Era-Interim (Simmons et al., 2006) refers to the re-analyses of atmospheric parameters produced by the European Center for Medium Weather Forecasts (ECMWF). It uses 4Dvariational analysis on a spectral grid and spans 1989 - present on a fixed $0.75^{\circ}$ grid (http://www.ecmwf.int/en/research/climate-reanalysis/era-interim ). The main parameters used in this study are zonal and meridional wind components at $10 \mathrm{~m}$ height, specific air humidity, air temperature at $2 \mathrm{~m}$, and sea surface temperature available at synoptic times $(00 \mathrm{~h}: 00$, 06h:00, 12h:00, 18h:00 UTC).

NCEP Climate Forecast System Reanalysis (CFSR) (http://rda.ucar.edu/pub/cfsr.html) is developed by the US NOAA NCEP. The data used for this study are from the NOAA's National Operational Model Archive and Distribution System (NOMADS), which is maintained by the NOAA's National Climatic Data Center (NCDC) (Saha et Co-authors, 2010). The coupled model consists of a spectral atmospheric model on T382 grid $(38 \mathrm{~km})$ with 64 hybrid vertical levels and the GFDL Modular Ocean Model. The atmosphere and ocean models are coupled with no flux adjustment. The NCEP-CFSR uses the Gridpoint Statistical Interpolation (GSI) data assimilation system for the atmosphere. Flow dependence for the background error variances is included as well as first order time interpolation to the observation. Variational quality control of observations (Andersson and Järvinen 1999) is also included. An ocean analysis for SST is also performed using Optimal Interpolation (OI). A full range of observations is used as in the other re-analyses which are quality controlled and bias corrected, including satellite radiances. Observations of ocean temperature and salinity are also used.

\subsection{Data collocation}

In this study we use satellite-buoy and satellite-satellite collocations to assess the accuracy of wind retrievals and to separate and correct for biases in radar calibration.

\subsubsection{Sattelite-buoy.}


The accuracy of wind retrievals is evaluated by comparing in-situ buoy measurements with quasi-simultaneous scatterometer data. Here we use satellite-buoy data pairs collocated in space and time. The spatial limit for collocation is set based on the spatial resolution of particular satellite wind product, which is $25 \mathrm{~km}$ for ERS-2 UWI, ASCAT, and QuikSCAT and increases to $50 \mathrm{~km}$ for ERS-1 and ERS-2 WNF. The temporal criterion is $30 \mathrm{~min}$ for all products. Only scatterometer retrievals indicated as selected, quality controlled solutions are used herein. The quality controls applied on remotely sensed data are from flags available with scatterometer L2b products.

\subsubsection{Satellite-satellite.}

Radar calibration issue for the WNF product is evaluated by collocating ERS-2 WNF and UWI products. The WNF and UWI data are available simultaneously over the same scatterometer swath, but at different spatial resolution of $50 \mathrm{~km} \times 50 \mathrm{~km}$ and $25 \mathrm{~km} \times 25 \mathrm{~km}$, respectively. The difference in spatial resolutions leads to a difference in the incidence angle range for WVCs between the two products. To achieve the consistency in geometry of observations, only WNF and UWI WVCs differing by less than $1^{\circ}$ in the incidence angle and separated by less than $50 \mathrm{~km}$ are selected. The collocated UWI data are then spatially interpolated on corresponding WNF WVCs. Collocated ERS-2 WNF and ERS-2 UWI data have much larger records (in comparison with satellite-buoy collocations). They are available over the global ocean because these collocations were produced from the same original scatterometer measurements. To reduce enormous number of these collocated observations, only their subset spanning January - March 2000 is further considered.

\subsection{Satellite-model}

ERA Interim and CFSR are available four times a day (00h:00; 06h:00; 12h:00; 18h:00 UTC) on their corresponding regular grids. Atmospheric re-analyses winds are interpolated in space and time over scatterometer swaths using a bilinear method.

\section{Validation method}

\subsection{Buoy comparison results}

Comparisons are performed for all valid collocated data available during the periods March 1992 - June 1996 for ERS-1 WNF, March 1996 - January 2001 for ERS-2 WNF, April 1997 - January 2001 for ERS-2 UWI, July 1999 - November 2009 for QSCAT, and April 2007 - March 2011 for ASCAT. Statistical parameters of scatterometer and buoy winds are summarized in Tables 2 and 3 (see Bentamy et al, 2011 for parameter's description). To avoid 
an impact of outliers a robust regression method of Street et al. (1988), which iteratively assigns weights to data, is applied. Outliers are filtered by excluding data with the assigned weight $<0.05$. The regression symmetrical coefficient $\left(b_{s}\right)$ in Tables 2,3 is produced by linear regression of satellite and buoy winds, $w_{\text {sat }}=b_{s} * w_{\text {buoy }}+a_{s}$, which accounts for errors in both, buoy and satellite data Two types of correlation coefficients are included. Scalar correlation $(\rho)$ for wind speed is the conventional Pearson's correlation coefficient. Wind direction correlation is evaluated as a vector correlation (Crosby et al., 1993). It provides a scalar measure of consistency between two vector fields and varies between -2 and +2 .

The agreement between buoy and scatterometer wind speeds is excellent. The wind speed correlation coefficients of all scatterometer products are higher than 0.87. The associated $b_{s}$ values are close to unity. The RMS differences (estimated from Bias and STD values) $<1.60 \mathrm{~m} / \mathrm{s}$ are lower than scatterometer accuracy specifications. The wind speed RMS at Tropical buoys is slightly weaker than that at NDBC. This is mainly related to difference in wind speed distributions over NDBC and Tropical network regions (e.g. Bentamy et al, 2008). One should notice that ERS-2 UWI and ASCAT have similar statistics. They rely on the use of same C-band geophysical model GMF to retrieve surface winds from the two scatterometers. Cmod5.n was developed on the basis of ERS-2 scatterometer backscatter coefficient measurements (Hersbach et al, 2007). Quite similar results are found for wind direction comparisons. Indeed, for ERS-1 WNF, ERS-2 WNF, QSCAT, and ASCAT the correlation coefficients characterizing NDBC and Tropical comparisons are higher than 1.20 and 1.60, respectively. The lowest wind direction correlations are found for ERS-2 UWI. Furthermore, except for ERS-2 UWI, STD values are lower than $20^{\circ}$.

\subsection{Reprocessing of ERS-1 and ERS-2 WNF wind retrievals}

Both ERS-1 WNF and especially ERS-2 WNF winds tend to be underestimated in comparison with buoy winds (Tables 1,2). This is associated with the calibration of ERS-1 and ERS-2 radars and GMF issues (e.g. Bentamy et al, 2013, see also references therein). Indeed, the reprocessing of ERS-2 wind retrievals based on the use of Cmod5.n GMF has improved correspondence with buoy data (Bentamy et al, 2013). Therefore, we achieve better consistency between ERS-1 and ERS-2 winds as a result of their reprocessing with Cmod5.n GMF. 
1 expected $\left(\sigma_{e}^{0}\right)$ backscatter coefficients to estimate radar calibration issues that may be still 2 present in the WNF products. The expected $\sigma_{e}^{0}$ is calculated from Cmod5.n forced by 3 collocated buoy wind velocity. The measured backscatter coefficient is evaluated from 4 scatterometer data following the Bentamy et al. (2008) approach. The azimuth dependence of $\sigma^{0}$ is represented by truncated Fourier series:

$$
\sigma^{0}=A_{0}+A_{1} \cos \chi+A_{2} \cos 2 \chi
$$

$\chi$ is the wind direction relative to antenna azimuth .

The coefficient $A_{0}$ in (1), referred to as the power coefficient, mainly carries the information on wind speed. The harmonic coefficient $\mathrm{A}_{1}$ describes the upwind and downwind asymmetry. The coefficient $A_{2}$ describes the difference in backscatter coefficient extrema. $A_{0}$, $A_{1}$, and $A_{2}$ are functions of wind speed, incidence angle, and polarization. According to the study objective dealing with wind speed consistency, we next focus on $\mathrm{A}_{0}$, which is calculated as:

$$
\mathrm{A}_{0}=\left(\sigma_{\mathrm{u}}^{0}+\sigma_{\mathrm{d}}^{0}+2 \sigma^{0}{ }_{\mathrm{c}}\right) / 4
$$

where $\sigma_{\mathrm{u}}^{0}, \sigma_{\mathrm{d}}^{0}, \sigma_{\mathrm{c}}^{0}$ are the upwind $\left(\chi=0^{\circ}\right)$, downwind $\left(\chi=180^{\circ}\right)$, and crosswind $(\chi=$ $90^{\circ}$ or $270^{\circ}$ ) values of the backscatter coefficient. Using buoy wind direction, we selected only those data that correspond within $\pm 10^{\circ}$ either to up-, down-, or cross-wind direction. The selected data are binned $1 \mathrm{~m} / \mathrm{s}$ in buoy wind speed and $0.2^{\circ}$ in incidence angle $(\theta)$, from which measured $\mathrm{A}_{0}$ is calculated based on (2). Only bins for which data count exceeds 10 are retained for investigations. The calculations are performed for $\mathrm{A}_{0}$ derived from ERS-1 WNF, ERS-2 WNF, and ERS-2 UWI backscatter measurements, $\sigma_{m}^{0}$.

For each wind speed and incidence angle the expected backscatter coefficients $\left(\sigma_{e}^{0}\right)$, calculated from Cmod5.n forced by collocated buoy winds, are used to estimate the expected $A_{0}$ based on (2). The best correspondence between expected and measured $A_{0}$ is found for ERS-2 UWI (Figures $1 \mathrm{~g}, 1 \mathrm{~h}, 1 \mathrm{i}$ ) that reflects better post flight backscatter calibration in the UWI product. Mean differences (resp. STD) between expected and measured power coefficients $\mathrm{A}_{0}$ for ERS-2 UWI are $-0.36 \mathrm{~dB}$ (resp. $1.08 \mathrm{~dB}$ ), $-0.60 \mathrm{~dB}(1.54 \mathrm{~dB}$ ), and $-0.57 \mathrm{~dB}$ $(1.10 \mathrm{~dB})$ for fore-, mid-, and aft-beam, respectively. The three associated correlation coefficients exceed 0.98 . The discrepancy between expected and measured power coefficients is stronger for ERS-1 WNF and ERS-2 WNF than that for ERS-2 UWI. It is more noticeable for low $\mathrm{A}_{0}$ corresponding to low winds. But, even for buoy winds $>3 \mathrm{~m} / \mathrm{s}$, the mean difference 
and STD reach $-1 \mathrm{~dB}$ and $2 \mathrm{~dB}$ for ERS-1 WNF and ERS-2 WNF, respectively. Correlation

2 between expected and measured power coefficients remain relatively high ( 0.95$)$ for the two

3 WNF products, but it is lower than that for the UWI.

Figure 1 illustrates a persistent overestimation of measured $\mathrm{A}_{0}$ in comparison with expected values, which is indicative of a low bias in ERS wind retrievals and suggests the need for correction of the WNF backscatter coefficients to reduce the bias in the scatterometer winds.

NRCS correction for ERS-1 WNF and ERS-2 WNF is based on a linear regression analysis of expected $\left(\sigma_{e}^{0}\right)$ and measured $\left(\sigma_{m}^{0}\right)$ NRCS using a linear regression analysis. Various regression analyses would be used to determine the linear relationship between measured and predicted $\sigma^{0}$ (e.g. Bentamy et al, 2011). However, one should notice that both $\sigma_{m}^{0}$ and $\sigma_{e}^{0}$ have their own uncertainties, neither measured nor expected $\sigma^{0}$ can be selected as a reference ('ground truth') for the analysis (e.g. Bentamy et al, 2011). Indeed, both sources have errors related to buoy wind and scatterometer backscatter coefficient measurements. Additional errors are related to the procedure of estimation of $\sigma_{e}^{0}$ and to the spatial and temporal separations between buoy and scatterometer data. In this study, the symmetrical regression analysis, also called the reduction of major axis is used (e.g. Trauth , 2007; Bentamy et al, 2011). It aims to minimize the distances separating regression fit and both, $\sigma_{m}^{0}$ and $\sigma_{e}^{0}$. Outliers, detected through the application of robust regression algorithm (Street et al, 1988), are excluded.

The regression is performed for each incidence angle bin because Figure 1 clearly indicates that NRCS correction should depend on $\theta$. Such kind of analysis requires a large sampling length of collocated buoy and scatterometer data. All available and valid NDBC and tropical (TAO and PIRATA) hourly data are used together and collocated with ERS-1 and with ERS-2 measurements based on space and time criteria described above. The resulting sampling lengths of ERS-1/buoy and ERS-2/buoy collocations are 17156 and 23405, respectively. These collocated data are split into two subsamples, which are randomly selected. The first subsample (67\% of collocated data) is used to determine the regression slope and intercept coefficients, whilst the second subsample is utilized for the validation.

of the corrected $\sigma^{\circ}$. Figure 2 shows examples of the validation results. It indicates the 31 mean differences between predicted $\sigma_{e}^{0}$ and measured $\sigma_{m}^{0}$ as a function of incidence angles. 32 Results related to ERS-1 and ERS-2 are shown in Figure 2a and Figure 2b, respectively. 
1 Dashed and Full and lines illustrate the results of $\left(\sigma_{e}^{0}\right.$ minus measured $\left.\sigma_{m}^{0}\right)$ and of $\left(\sigma_{e}^{0}\right.$ 2 minus corrected $\sigma_{m}^{0}$ ), respectively. Measured $\sigma_{m}^{0}$ tend to be overestimated with respect to the 3 expected backscatter coefficients, $\sigma_{e}^{0}$, (Figure 2) Not surprisingly, the results are in agreement 4 with the power coefficient $\mathrm{A}_{0}$ in Figure 1 . The difference, $\sigma_{e}^{0}-\sigma_{m}^{0}$, is reduced for the corrected measured backscatter coefficients calculated from the application of the symmetrical regression results. The correction reduces the mean difference $\sigma_{e}^{0}-\sigma_{m}^{0}$ by about 30\%. The lowest mean and standard deviation (not shown) are found for inner swath locations (low incidence angles). For instance, the associated RMS difference related to ERS-1 midbeam vary between 1 and $1.5 \mathrm{~dB}$ for $\theta<25^{\circ}$, while RMS values reach $1.90 \mathrm{~dB}$ for $\theta>40^{\circ}$.

To further assess the quality of the correction procedure reliability, corrected ERS-2 WNF $\sigma^{0}$ are compared to ERS-2 UWI over global ocean. Indeed, the latter exhibit the best comparison results versus predicated backscatter coefficient (Figure $1 \mathrm{~g}$ ), h), and i)). The comparison is performed based on the use of collocated ERS-2 WNF and UWI (section 2.4). Figure 3 shows mean differences between ERS-2 UWI and ERS-2 WNF backscatter coefficients as a function of incidence angles. The statistics are estimated from remotely sensed data collected from January through March 2000. Dashed and full lines illustrate the result associated with uncorrected and corrected ERS-2 WNF $\sigma^{\circ}$, while the colors aim to distinguish the results associated with each beam like in buoy comparisons (Figure 2) the uncorrected ERS-2 WNF $\sigma^{\circ}$ tend to be overestimated versus ERS-2 UWI. On average, biases related to the uncorrected $\sigma^{\circ}$ differences fall within $-0.20 \mathrm{~dB}$ and $-0.10 \mathrm{~dB}$ range and are reduced as a result of the correction. Indeed the biases are lower than $0.07 \mathrm{~dB}$.

Based on the method and the related results described in (Bentamy et al, 2013), ERS-1 and ERS-2 scatterometer wind speeds are reprocessed using the corrected backscatter coefficients and Cmod5.n GMF. As for ASCAT and QSCAT, these newly reprocessed ERS-1 and ERS-2 retrievals are referred as ERS-1/N and ERS-2/N. The gross statistics of deviations from buoy data for these new retrievals are listed in brackets in Table 2 and Table 3. Because neither of buoys locates in cold SST $<5^{\circ} \mathrm{C}$, the results for QSCAT/N are very close to those for QSCAT and therefore not shown. Although, the statistics obtained for ASCAT L2b and 30 ASCAT/N are slightly different, the results are statically comparable. Indeed, the main impact of ASCAT bias correction relies on high wind conditions (wind speed exceeding $18 \mathrm{~m} / \mathrm{s}$ ). The latter are undersampled in buoy and ASCAT collocated data set. The main changes are found 
1 for the reprocessed ERS winds in comparison with WNF winds. Indeed, the reprocessed ERS-

21 and ERS-2 winds show significant reduction in the time mean as well as in RMS wind 3 speed differences. The new bias values are quite small, and the associated RMS differences are even lower that for ERS-2 UWI, QSCAT, and ASCAT.

The results in Tables 2 and 3 reflect statistics averaged over the period of operation of each satellite. It is important to ensure that validation results are not time dependent. This could be determined by examining differences, in terms of bias and STD, between buoy and scatterometer data as a function of time. The results are illustrated in Figure 4 and 5 for NDBC and Tropical buoy comparisons, respectively. For each month of comparison periods, difference between available collocated buoy and scatterometer wind speeds are arithmetically averaged and the associated STD are calculated. Full lines indicate time series of monthly mean differences, while dashed lines indicate bias \pm STD. Along the duration of each scatterometer period, the related monthly biases are quite close to the total bias (Tables 2 and 3). No significant time changes are depicted. Based on mean differences and the associated STD, results shown in Figures 4 and 5 state that no systematic biases are found. Changes of a few tenths of $\mathrm{m} / \mathrm{s}$ are mainly due to changes in sampling lengths of collocated data and/or to wind seasonal variability. For instance there is a factor of 3 between the number of collocated NDBC and ERS-1 and NDBC and QSCAT. The change in sampling lengths arises from changes between scatterometer sampling schemes and especially on changes in the number of buoys available for the collocation. For instance, the numbers of Tropical buoy available for ERS-1, ERS-2, QSCAT, and ASCAT collocations are on average about of 19, 24, 32 , and 28, respectively. As expected the inter-annual wind distributions may also have significant impact on buoy and scatterometer comparisons. For instance, the percentage of low winds (lower than $3 \mathrm{~m} / \mathrm{s}$ ) reported from NDBC buoys reaches a maximum of $37 \%$ in August 1992, whereas it is only about 20\% during summer months (June-July-August). Low winds that are not adequately detected by ERS $1 / 2$ lead to a negative bias between NDBC and ERS-1 wind speeds. Monthly difference time series calculated from NDBC and scatterometer winds (Figure 4) indicate different trends for ERS-1 and ERS-2 biases. The latter tends to be negative. Such changes between ERS-1 and ERS-2 bias trends, is mainly relied on changes in

30 low wind speed distribution derived from NDBC buoy measurements. Indeed, the sampling lengths of NDBC low wind speeds $(<4 \mathrm{~m} / \mathrm{s})$, reported from collocated buoy and scatterometer data, are of 1175 and 1935 for ERS-1 and ERS-2 periods, respectively. We may notice that during overlapping periods of any pair of scatterometers, their associated biases are very 
1 close. However, some discrepancies are depicted. For instance, Figure 4 indicates QSCAT/N

2 and ASCAT/N bias difference during the period April - December 2007 when original 3 ASCAT retrievals are estimated as "real", not ENW at 10m, winds (Bentamy et al, 2008).

4 Correlation coefficient time series (not shown) vary mostly between 0.88 and 0.97 . The highest values are found for QSCAT/N and ASCAT/N whereas the lowest are related to ERS1 and ERS-2 and especially for summer months. This is clearly due to the sampling issues mentioned above.

\section{Global consistency analysis}

In the previous section, we established that ERS-1/N, ERS-2/N, QSCAT/N, and ASCAT/N exhibit quite similar statistics with respect to buoy data. Although such comparisons remain the most reliable method to estimate the quality of remotely sensed data, it is spatially limited. This section aims to investigate, based on statistical analysis, the consistency of the four scatterometer wind sources at global as well as at regional and local scales. For such purpose, comparisons are performed versus ERA Interim and CFSR 10m wind speed estimates. This analysis aims first to assess the long term consistency of the remotely sensed data, and secondly to assess the comparisons of scatterometer and NWP (wind speeds at various spatial and temporal scales. CFSR as well as ERA Interim are considered as references. However, they are assumed ensuring long time series consistency of surface winds.

The purpose aiming to assess the consistency of long time series of surface wind speed retrievals based on the use of NWP requires ensuring that their long time variations are not scatterometer dependant. Indeed, both numerical models assimilate ERS-1, ERS-2, QuikSCAT and ASCAT observations. To meet this requirement, monthly ERA Interim and CFSR wind speed anomalies are calculated over North, Tropical, and South Atlantic Oceans during the period March 1992 - March 2011 (not shown). The departures from annual mean concurrent with start and/or end periods of a given scatterometer observations would be used as dependency indicators. The analysis of anomaly time series do not lead to any significant change associated with change in scatterometer availability for assimilation processing. Therefore, hereafter, ERA Interim and CFSR wind speeds are assumed time consistent.

To reduce the impact of difference in spatial resolutions for NWP and scatterometer winds, both are averaged over $1^{\circ} \times 1^{\circ}$ grid cells over scatterometer swaths. The resulting collocated data are monthly averaged. The monthly averages are arithmetically formed on the $1^{\circ} \times 1^{\circ}$ grid using all available and valid data falling within the grid cell. As expected, the 
1 sampling lengths of $1^{\circ} \times 1^{\circ}$ collocated NWP and remotely sensed data rely on scatterometer

2 characteristics. On average, in inter-tropical oceanic basins the monthly number of collocated data at grid of $1^{\circ}$ is about 15 for ERS- 1 and ERS-2 and of 40 for QSCAT and ASCAT. At high latitudes, this number reaches or exceeds 30 for ERS-1 and ERS-2, and 70 for QSCAT and ASCAT.

\subsection{Global spatial distributions}

The monthly averages are utilized to estimate annual wind speed means during operating period of each scatterometer. Spatial variability of annual scatterometer wind speeds (first column) are shown in Figures 6 and 7, along with mean (second column) and STD (Third column) differences between NWP and scatterometer data, for CFSR and ERA Interim comparisons, respectively. Spatial statistics associated to ERS-1/N, ERS-2/N, QSCAT/N, and to ASCAT/N are shown in first, second, third, and fourth Figure rows, respectively.

Some difference patterns revealed in Figures 6 and 7 are inherent to the characteristics of scatterometer and NWP wind determinations. For instance, model surface wind speeds are earth-relative, whereas scatterometer retrievals are surface-relative. Therefore, surface currents may lead to differences between NWP and remotely sensed wind data (e.g. Quilfen $e t$ $a l$, 2001). Rain impact on scatterometer measurements may also induce a departure from model estimates. Indeed, scatterometer, and especially, radars operating at $\mathrm{Ku}$ band such as QSCAT, are rain affected. In the presence of rain, Ku-band backscatter coefficients are affected by the roughening of the sea surface by rain drops and also by scattering and absorption by rain drops in the atmosphere. (Sobieski et al, 1999) showed that rain impact on QSCAT retrievals may lead to an overestimation reaching $2 \mathrm{~m} / \mathrm{s}$ in the tropical rainy regions. Another source of the difference between model and scatterometer winds is associated to the atmospheric stability effect. Indeed, NWP wind estimation includes air-sea stratification, whereas scatterometer winds are equivalent neutral wind. Neutral wind speeds are stronger, on average, than stability-dependent wind speeds (e.g. Mears et al, 2001). To assess the stability impact, $10 \mathrm{~m}$ neutral winds are calculated from ERA Interim $10 \mathrm{~m}$ stability-dependent wind speed, air and sea surface temperatures, and specific air humidity based on the use of COARE3.0 bulk parameterization (Fairall et al, 2003). Comparisons between ERA Interim $10 \mathrm{~m}$ neutral and $10 \mathrm{~m}$ stability-dependent wind speeds are performed for ERS-1, ERS-2, QSCAT, and ASCAT periods (not shown). The mean differences between the two ERA Interim wind speeds are of about $0.20 \mathrm{~m} / \mathrm{s}$ for the four scatterometer periods. It is also found 
1 that differences vary as a function of oceanic zone and season. For instance, along north hemisphere western boundary currents, the difference reaches $0.40 \mathrm{~m} / \mathrm{s}$ during winter season.

The comparisons of mean wind speed patterns (Figures 6 and 7) are not straightforward due to differences between scatterometer sampling schemes. To assess the impact of sampling schemes, monthly-averaged winds estimated from only CFSR data collocated on one hand with ERS-2/N and on other hand with QSCAT/N during 2000, are compared. It is found (not shown) that differences between the two annual CFSR wind speeds may reach $1 \mathrm{~m} / \mathrm{s}$, especially at high latitudes where surface wind is more variable. Results shown in Figures 6 and 7 indicate that the spatial variability of wind speeds from all scatterometers generally show similar features. Furthermore, they exhibit quite similar magnitudes over the global ocean. For instance, high winds exceeding $10 \mathrm{~m} / \mathrm{s}$ are found in northern (north $50^{\circ} \mathrm{N}$ ) and southern (south $45^{\circ} \mathrm{S}$ ) latitudes. The lowest winds are generally located along the equatorial zones. Mean wind speed biases calculated with respect to CFSR (Figure 6) reveal that the associated patterns are quite similar. Same results are found for bias determined with respect to ERA Interim (Figure 7). For the four scatterometers, about $95 \%$ of bias absolute values are lower than $1 \mathrm{~m} / \mathrm{s}$. Global distributions of both mean differences and STD of ERS-1/N and ERS-2/N are remarkably similar. Similar results are found for QSCAT/N and ASCAT/N and especially for CFSR comparisons. These results are relied on the scatterometer sampling schemes characteristics. On average, the four scatterometer winds tend to be slightly overestimated compared to CFSR and ERA Interim re-analyses. As expected, the four STD spatial distributions exhibit small (lower than $1 \mathrm{~m} / \mathrm{s}$ ) and high (great than $2 \mathrm{~m} / \mathrm{s}$ ) values in the tropical and high latitude regions, respectively. Both regions are characterized by low and high wind variablities. Surface winds occurring over extra-tropical regions are known dominated by more dynamic synoptic variability as compared to less variable tropical winds.

Although, NWP and scatterometers are in good agreements, significant departures are found at some specific regions. For instance, ERS-1/N winds are underestimated with respect to CFSR estimates (Figure 6b) along south trade wind zone in the Atlantic Ocean. Indeed, mean differences between CFSR and ERS-1/N annual winds are about $0.40 \mathrm{~m} / \mathrm{s}$, and reach $0.80 \mathrm{~m} / \mathrm{s}$ at some locations. Similar difference pattern, even though slightly lower, is found for CFSR and ERS-2/N comparison (Figure 6e). For CFSR and QSCAT/N (Figure 6h) as well as for CFSR and ASCAT/N (Figure 6k) comparisons do not lead to any significant patterns of wind differences along south Atlantic trade wind area. These specific difference patterns are also depicted from ERA Interim and scatterometer comparisons (Figure 7b, e, h, and k). 
1 Interim south Atlantic trade winds decrease from 1992 through 2011.

Noticeable differences are depicted along the three ocean equatorial areas. Scatterometer monthly winds are overestimated with respect to NWP estimates. The highest departures are found for ASCAT and especially for QSCAT/N. These equatorial difference patterns are more pronounced for ERA-Interim comparisons. For instance, mean difference between ERA-Interim and QSCAT/N may reach $2 \mathrm{~m} / \mathrm{s}$. Such difference behaviors along the equator may partly rely on impact of rain (non detected through quality control procedure), especially for QSCAT/N, current on scatterometer retrievals, and of stability (see above). However, such impacts cannot account for the total differences between ERA Interim and scatterometer winds along equatorial zones. Indeed, these equatorial differences are not found for CFSR and scatterometer comparisons (Figure 6). The former exhibit lower difference values. Somewhat high discrepancies between ERA Interim and scatterometer winds are also depicted along western boundary current regions. ERS-1/N, ERS-2/N, and QSCAT/N winds are slightly overestimated compared to ERA Interim. These patterns are not found for ERA Interim and ASCAT/N and for CFSR and scatterometer comparisons.

\subsection{Long time series}

In section above, the consistency of scatterometer retrievals has been assessed through the spatial differences versus CFSR and ERA Interim analyses. Such consistency would be further assessed through the investigation of long time series of surface wind speeds derived from scatterometers and NWP over ocean basins or at some locations of interest.

Figures 8 and 9 show time series of yearly-averaged wind speeds estimated from available monthly-averaged collocated CFSR and scatterometer. and from ERA Interim and scatterometer data, respectively. They also show annual mean wind speeds calculated from 6hourly CFSR and ERA Interim analyses (dashed lines). They are calculated for five oceanic zones : Northern high-latitudes $\left(50^{\circ} \mathrm{N}-70^{\circ} \mathrm{N}\right)$, Northern mid-latitudes $\left(20^{\circ} \mathrm{N}-40^{\circ} \mathrm{N}\right)$, tropical $\left(10^{\circ} \mathrm{S}-10^{\circ} \mathrm{N}\right)$, Southern mid-latitudes $\left(40^{\circ} \mathrm{S}-20^{\circ} \mathrm{S}\right)$, and Southern high-latitudes $\left(70^{\circ} \mathrm{S}-\right.$ $50^{\circ} \mathrm{S}$ ). Changes of mean values associated with changes of remotely sensed data sources are related in part to the sampling scheme issues. Indeed, annual means derived from CFSR (Figure 8) as well from Era Interim (Figure 9) show small change over time, except for the period beyond 2009, and along southern high latitudes (Figure 8e and 9e). But, stronger changes are present in the time series derived from the collocated data, including discontinuities associated with changes of satellites, thus associated with sampling schemes. 
1 Noticeably, similar discontinuities are present in scatterometer wind averages emphasizing 2 again the sampling impacts. Obviously, changes in annual wind speeds estimated from ERS$3 \quad 1 / \mathrm{N}$ and ERS-2/N are related to the sampling issues because similar changes are depicted for 4 the collocated CFSR and ERA Interim data. Similar results are found for ERS-2/N and QSCAT/N, except at tropical zone (Figure $8 \mathrm{c}$ and 9c). Annual winds calculated from QSCAT/N over the tropics tend to be overestimated due to rain impact. Although, QSCAT/N and ASCAT/N yearly mean values are close during overlapping period (2008 - 2009), a slight overestimation (resp. underestimation) of QSCAT/N with respect to ASCAT/N are found in tropical and midlatitude areas (resp. northern and southern high latitudes). The latter meet the results shown in (Bentamy et al, 2011), and in (Grodsky et al, 2012). However, one should notice that departure between QSCAT/N and ASCAT/N mean values do not exceed $0.20 \mathrm{~m} / \mathrm{s}$.

Further investigation of remotely sensed data consistency as well as of comparison between satellite and NWP are performed at some specific locations for monthly time scales. Figures 10 and 11 show time series of monthly-averaged wind speeds estimated from collocated scatterometers and CFSR, and from scatterometers and ERA Interim, respectively. They are shown at locations supposed representing different surface wind characteristics associated with North Atlantic $\left(59^{\circ} \mathrm{N} 11^{\circ} \mathrm{W}\right)$, Gulf stream $\left(41^{\circ} \mathrm{N} 66^{\circ} \mathrm{W}\right)$, the Mediterranean Sea $\left(41^{\circ} \mathrm{N} 6^{\circ} \mathrm{E}\right)$, equatorial $\left(0^{\circ} \mathrm{N} 10^{\circ} \mathrm{W}\right)$, and Bay of Bengal $\left(15^{\circ} \mathrm{N} 90^{\circ} \mathrm{E}\right)$ temporal wind patterns. Furthermore, moored buoy measuring winds are also available at these specific locations or nearby. They would be valuable for triplet buoy / scatterometer / NWP collocation analysis.

At the north Atlantic location (Figure 10a and 11a), both scatterometer and NWP wind speeds exhibit very similar wind patterns. The two types of wind sources lead to the expected robust seasonal variation of surface wind speed. Most of maximum and minimum winds occur during north hemisphere winter (December, January, February (DJF)) and summer (June, July, August (JJA)), respectively. However, one should notice that the inter-annual variability is significant. Despite of sampling scheme impact, the four scatterometer retrievals are consistently higher than CFSR as well as than ERA Interim wind estimates.

The scatterometer as well as NWP wind speed variablities at the Atlantic northwest 30 location (Figures $10 \mathrm{~b}$ and $11 \mathrm{~b}$ ) illustrate the typical annual features of surface wind occurring 31 in the midlatitude of the North Atlantic and the Pacific Oceans. They are mainly characterized by a robust seasonal variability where the maximum and minimum occur in winter and summer seasons, respectively. The month to month variability derived from scatterometer and 
1 NWP agree well. However, one should notice that departure found between ERA Interim and

2 ERS-1/N during the period 1992 through 1994 is higher than that depicted from ERS-1/N and

3 CFSR comparison.

At the location of Gulf of Lion in the Mediterranean Sea (Figure 10c and 11c), scatterometer and NWP winds reveal similar month to month variablities characterized by a seasonal features. The highest and lowest winds occur during winter and summer seasons. Due to sampling issues, monthly estimated from collocated NWP, ERS-1/N, and ERS-2/N data are more variable. Monthly scatterometer winds are consistently higher than ERA Interim estimates (Figure 11c), while no systematic bias is found out from CFSR comparisons (Figure 10c). The comparisons of monthly winds derived from buoys moored in Gulf of Lion (buoys WMO61001 (43.3 $\left.{ }^{\circ} \mathrm{N} 7.8 \mathrm{E}\right)$ and WMO61002 $\left.\left(42.1^{\circ} \mathrm{N} 4.7^{\circ} \mathrm{E}\right)\right)$ and scatterometers (QSCAT/N and ASCAT/N) do not reveal any overestimation of scatterometer estimates (not shown).

Time series of wind speeds at equatorial site (Figure 10d and Figure 11d) reveal less robust seasonal variability. The wind variability is more characterized by large interannual patterns. Even though NWP and scatterometer exhibit quite similar variablities, the month to month agreement is quite poor compared to previous sites. This is mostly pronounced for ERS-1/N and ERS-2/N. Furthermore, due to wind speed distribution along the equatorial region, the departure between ERA Interim and the four scatterometer winds is further highlighted. Better results are drawn from CFSR and scatterometer wind time series comparisons. The latter are similar to those obtained from the comparisons of monthly winds estimated from PIRATA buoy $\left(0^{\circ} \mathrm{N}, 10^{\circ} \mathrm{W}\right)$ and from scatterometers (ERS-2/N, QSCAT/N, and ASCAT/N).

The wind speed variations obtained at location in the bay of Bengal of the Indian Ocean (Figures 10e and 11e) exhibit a major peak occurring in summer season and related to the Indian monsoon season, while a second weaker peak occurs mostly in January when the region experiences winter weather conditions. The difference between the two peaks indicates that the climate in this region is overwhelmingly controlled by the monsoon. Although, ERA Interim winds are slightly underestimated (Figure 11e), their comparisons to scatterometer are of same order that found for CFSR.

\section{Summary and discussion}

Twenty years of scatterometer measurements and wind retrievals are investigated to assess the consistency between the various satellite missions. This study is a continuation of 
1 those previously set up to assess the comparisons of scatterometer winds derived from 2 ASCAT and QSCAT (Bentamy et al, 2012 and Grodsky et al, 2012), and from ERS-2 and QSCAT (Bentamy et al, 2013). It aims at the characterization of the source of errors yielding to significant differences between scatterometer retrievals and reference data, and at the correction of systematic biases between scatterometer missions.

In this study focuses on the four scatterometers missions: ERS-1 (March 1992 - May 1996), ERS-2 (March 1996 - January 2001), QSCAT (July 1999 - November 2009), ASCAT (April 2007 - March 2011), which represent more than two decades of the global ocean winds. The study investigates the long-term consistency of the scatterometer missions. For such purpose, bias corrections found for QSCAT and ASCAT and detailed in (Bentamy et al, 2012, Grodsky et al, 2012) are applied without any further investigations. These datasets are referred as QSCAT/N and ASCAT/N. The results drawn from (Bentamy et al, 2013) dealing with the assessment of ERS-2 and QSCAT are used as guideline for further investigation of ERS-2 winds and then for ERS-1.

The wind speed retrieval consistency is mainly based on the use of collocated moorings and scatterometer data. Similar space and time collocation procedure is applied for the four scatterometers. The analysis of collocated data clearly shows that the source of WNF ERS-1 and ERS-2 wind underestimation with respect to buoys is related in part with the backscatter coefficient bias. This bias characterizes the mean differences between measured $\left(\sigma_{m}^{0}\right)$ and expected ( $\sigma_{e}^{0}$, estimated from buoy wind and Cmod5.n GMF) backscatter coefficients. ERS-1 and ERS-2 backscatter coefficient biases do not exhibit similar behavior as a function of $\sigma^{\circ}$ and incidence angle ranges. For each ERS beam and each incidence angle bin, a relationship relating difference of $\sigma_{e}^{0}$ and $\sigma_{m}^{0}$ as a function of $\sigma_{m}^{0}$ is determined and used for backscatter coefficient correction. This approach has a serious shortcoming issues. Indeed, moorings have a limited geographical coverage and the associated reported and collocated atmospheric and oceanic conditions are not representative well of for global conditions, especially at high latitudes where buoys are almost missing. However over the global ocean, it is found that corrected ERS-2 NRCS compare better with ERS-2 UWI NRCS (assumed well calibrated) than uncorrected NRCS.

The corrected ERS-1 and ERS-2 NRCS are used for reprocessing wind velocity based on CMOD5.n GMF. As expected, the new ERS-1 and ERS-2 winds (referred as ERS-1/N, and ERS-2/N) exhibit better comparisons with independent mooring data not used for the 
1 correction procedure. Indeed, both mean and STD characterizing buoy and ERS-1/N and buoy

2 and ERS-2/N are reduced significantly. They of same order that found for QSCAT/N and $3 \quad$ ASCAT/N.

4 The determination of ERS-1/N , ERS-2/N, QSCAT/N, and ASCAT/N retrievals over global ocean and from March 1992 through March 2011, leads to further investigations of consistency at global and regional scales and as a function of time. The four remotely sensed data sources show very similar spatial and temporal patterns in agreement with the main known wind distributions. The main discrepancies are found along the equatorial areas where ERS-1/N and ERS-2/N winds are slightly higher than QSCAT/N and ASCAT/N. The study of the long-term wind speed time series, do not show any step change associated with the change of scatterometer. The differences between two scatterometer winds, operating at same dates, rely on their space and time sampling schemes

These new datasets derived from "calibrated" scatterometer measurements for a period exceeding 20 years would be useful for several studies aiming at the characterization of longterm of surface parameters such as wind stress, wind stress curl, latent and sensible heat fluxes at various spatial and temporal scales. We do believe they provide a better resource for such studies, which are ongoing research.

Acknowledgements. This research was supported by the NASA International Ocean Vector 21 Wind Science Team (NASA NNXIOAD99G), and by TOSCA (Terre, Océan, Surfaces 22 continentales, Atmosphère) project. We thank D. Croizé-Fillon, J. F. Piollé, F. Paul, and 23 IFREMER/CERSAT for data processing support. The authors are grateful to ESA, 24 EUMETSAT, CERSAT, JPL, Météo-France, NDBC, PMEL, and UK MetOffice for providing numerical, satellite, and in-situ data used in this study. 
Andersson, E. and Järvinen, H., 1999: Variational quality control. Q. J. R. Meteorol. Soc., $125,697-722$

Ayina L. H., A. Bentamy, A. Mestas-Nunez, G. Madec, 2006: The impact of satellite winds and latent heat fluxes in a numerical simulation of the tropical Pacific Ocean. Journal of Climate, 19(22), 5889-5902. http://dx.doi.org/10.1175/JCLI3939.1

Bentamy, A., P. Queffeulou,, Y. Quilfen, K. Katsaros,1999: Ocean surface wind fields estimated from satellite active and passive microwave instruments, IEEE T. Geoscience and Remote Sensing, 37 (5) , 2469-2486

Bentamy A., K B. Katsaros, M. Alberto, W. M. Drennan, E. B. Forde, 2002: Daily surface wind fields produced by merged satellite data. American Geophys. Union, Geophysical Monograph Series Vol. 127, 343-349.

Bentamy, A., D. Croize-Fillon, and C. Perigaud, 2008: Characterization of ASCAT measurements based on buoy and QuikSCAT wind vector observations, Ocean Sci., 4, $265-274$.

Bentamy, A., K. Katsaros, P. Queffeulou, 2011 : Satellite Air - Sea fluxes. In Remote Sensing of the Changing Oceans. Springer Verlag Ed. (Tang, DanLing (Ed.)). http://archimer.ifremer.fr/doc/00030/14101/. 141 - 168.

Bentamy, A., S. A. Grodsky, J. A. Carton, D. Croizé-Fillon, and B. Chapron, 2012: Matching ASCAT and QuikSCAT winds, J. Geoph. Res., 117, C02011, doi:10.1029/2011JC007479.

Bentamy A., Grodsky S. A., Chapron B., Carton J. A., 2013: Compatibility of C- and Kuband scatterometer winds: ERS-2 and QuikSCAT. J. Marine System 117-118, 72-80

Blanke, B., S. Speich, A. Bentamy, C. Roy, and B. Sow , 2005: Modeling the structure and variability of the southern Benguela upwelling using QuikSCAT wind forcing, $J$. Geophys. Res., 110 ,C07018, doi:10.1029/2004JC002529.

Bourassa, M. \& Co-Authors, 2010: Remotely Sensed Winds and Wind Stresses for Marine Forecasting and Ocean Modeling in Proceedings of OceanObs'09: Sustained Ocean Observations and Information for Society (Vol. 2), Venice, Italy, 21-25 September 2009, Hall, J., Harrison, D.E. \& Stammer, D., Eds., ESA Publication WPP-306, doi:10.5270/OceanObs09.cwp.08

Crapolicchi R., G. De Chiara, A. Elyouncha, P. Lecomte, 2012: ERS-2 Scatterometer: Mission Performances and Current Reprocessing Achievements, Geoscience and Remote Sensing, IEEE Transactions, Vol. 50, Issue: 7.

Crosby, D.S., L.C. Breaker,and W.H. Gemmill, 1993: A proposed definition for vector correlation in geophysics: theory and application. Journal of Atmospheric and Oceanic Technology, 10, 355 - 367.

De Chiara, G., and H. Hersbach, 2009. ERS-2 scatterometer cycle report. ESA publication. http://earth.esrin.esa.it/pcs/ers/scatt/reports/pcs_cyclic/wscatt_rep_144.pdf. pp. 63.

Ebuchi, N., H. C. Graber, and M. J. Caruso, 2002: Evaluation of wind vectors observed by QuikSCAT/SeaWinds using ocean buoy data. J. Atmos. Oceanic Technol., 19, 20492069.

Fairall CW, Bradley EF, Hare JE, Grachev AA, Edson JB. 2003.Bulk parameterization of airsea fluxes: updates and verification for the COARE algorithm. Journal of Climate 16: 571-591, DOI:10.1175/1520- 0442(2003)016<0571:BPOASF>2.0.CO;2.

Freilich M. H and R. S. Dunbar, 1999: The accuracy of the NSCAT 1 vector winds: Comparisons with National Data Buoy Center buoys. Jour. Geophys. Res. Vol. 104, No C5, 11,231 - 11,246. 
Graber H. C., N. Ebutchi, R. Vakkayil, 1996: Evaluation of ERS-1 scatterometer winds with wind and wave ocean buoy observations, Tech. Report, RSMAS 96-003, Division of Applied Marine Physics, RSMAS, Univ. of Miami, Florida 33149-1098, USA, 58 pp.

Grima, N., A. Bentamy, K. Katsaros, and Y. Quilfen, 1999: Sensitivity of an oceanic general circulation model forced by satellite wind stress fields, J. Geophys. Res., 104, 7967-7989, doi:10.1029/1999JC900007.

Grodsky, S. A., V. N. Kudryavtsev, A. Bentamy, J. A. Carton, and B. Chapron, 2012. Does direct impact of SST on short wind waves matter for scatterometry?, Geophys. Res. Lett. 39, L12602, DOI: 10.1029/2012GL052091.

Hersbach, H., A. Stoffelen, and S. de Haan , 2007: An improved C-band scatterometer ocean geophysical model function: CMOD5, J. Geophys. Res., 112, C03006, doi:10.1029/2006JC003743

Hersbach H., 2010: Comparison of C-Band Scatterometer CMOD5.N Equivalent Neutral Winds with ECMWF. J. Atmos. Oceanic Technol., 27, 721-736. doi: http://dx.doi.org/10.1175/2009JTECHO698.1

Katsaros, K. B., E. B. Forde, P. Chang and W. T. Liu, 2001: QuikSCAT facilitates early identification of tropical depressions in 1999 hurricane season. Geophys. Res. Lett., 28, 1043-1046

Le Marshall, J., L. Leslie, R. Morison, N. Pescod, R. Seecamp and C. Spinoso (2000): Recent developments in the continuous assimilation of satellite wind data for tropical cyclone track forcasting. Adv. Space Res., 25, 1077-1080.

Mears CA, Smith DK, Wentz FJ. 2001. Comparison of Special Sensor Microwave Imager and buoy-measured wind speeds from 1987-1997. Journal of Geophysical Research 106: 11 719-11 729, DOI: 10.1029/1999JC000097

Penven, P., V. Echevin, J. Pasapera, F. Colas, and J. Tam, 2005: Average circulation, seasonal cycle, and mesoscale dynamics of the Peru Current System: A modeling approach, J. Geophys. Res., 110, C10021, doi:10.1029/2005JC002945.

Quilfen, Y., 1995: ERS-1 off-line wind scatterometer products. IFREMER Tech. Rep., 75 pp.

Quilfen, Y., Chapron, B., Vandemark, D., 2001, "The ERS Scatterometer Wind Measurement Accuracy: Evidence of Seasonal and Regional Biases", Journal of Atmospheric and Oceanic Technology, vol. 18, no. 10, pp. 1684-1697.

Saha, S., and Coauthors, 2010: The NCEP Climate Forecast System Reanalysis. Bull. Amer. Meteor. Soc., 91, 1015-1057.

Simmons A, Uppala S, Dee D, Kobayashi S. 2006: ERA-Interim: New ECMWF reanalysis products from 1989 onwards. ECMWF Newsletter 110: 26 - 35.

Sobieski, P. W., C. Craeye, and L. F. Bliven, 1999: Scatterometric signatures of multivariate drop impacts on fresh and salt water surfaces, Int, J. Remote Sens., 20, 2149-2166.

Street, J. O., R. J. Carroll, and D. Ruppert, 1988: A Note on Computing Robust Regression Estimates via Iteratively Reweighted Least Squares, The American Statistician, 42, pp. $152-154$

Sudha A. K. And C.V..K Prasada Rao, 2013: Comparison of Oceansat-2 scatterometer winds with buoy observations over the Indian Ocean and the Pacific Ocean. Remote sensing Letters. Vol. 4, Issue 2, doi:10.1080/2150704X.2012.713140. 171-179 pp.

Trauth M. H., 2007: Matlab Recipes for Earth Sciences. $2^{\text {nd }}$ ed. Springer Verlag, 288pp.

Verspeek, J.; A. Stoffelen, M, Portabella, H. Bonekamp, C. Anderson, and J.F. Saldana, 2010: Validation and Calibration of ASCAT Using CMOD5.n, IEEE Transactions on Geoscience and Remote Sensing, 48, 386-395, doi: 10.1109/TGRS.2009.2027896

Wentz, F. J and D. K. Smith, 1999: A model function for the ocean-normalized radar cross section at $14 \mathrm{GHz}$ derived from NSCAT observations. J. Geophys. Res., 104, 11 499-11 514 


\section{Tables}

Table 1: Summary of scatterometer characteristics.

\begin{tabular}{|c|c|c|c|c|c|c|c|}
\hline Scatterometer & Period & Cycle & Frequency & GMF & $\begin{array}{l}\text { L2b } \\
\text { version }\end{array}$ & WVC & Agency \\
\hline \multirow{5}{*}{ ERS-1 } & $\begin{array}{c}\text { Aug } 1991-\text { Mar } \\
1992\end{array}$ & 3 days & \multirow{5}{*}{$\begin{array}{c}\text { C-band } \\
(5.3 \mathrm{GHz} \text {, } \\
5.7 \mathrm{~cm})\end{array}$} & \multirow{5}{*}{ CMODIFR2 } & \multirow{5}{*}{ WNF2 } & \multirow{5}{*}{$50 \mathrm{~km}^{2}$} & \multirow{5}{*}{ IFREMER } \\
\hline & $\begin{array}{c}\text { Apr } 1992-\text { Dec } \\
1993\end{array}$ & 35 days & & & & & \\
\hline & $\begin{array}{c}\text { Dec } 1993-\text { Apr } \\
1994\end{array}$ & 3 days & & & & & \\
\hline & $\begin{array}{c}\text { Apr } 1994-\text { Mar } \\
1995\end{array}$ & $\begin{array}{c}168 \\
\text { days }\end{array}$ & & & & & \\
\hline & $\begin{array}{c}\text { Mar 1995 - May } \\
1996\end{array}$ & 35 days & & & & & \\
\hline \multirow{2}{*}{ ERS-2 } & Apr 1995 - Jan 2001 & 35 days & \multirow{2}{*}{$\begin{array}{c}\text { C-band } \\
(5.3 \mathrm{GHz} \text {, } \\
5.7 \mathrm{~cm})\end{array}$} & CMODIFR2 & WNF2 & $50 \mathrm{~km}^{2}$ & IFREMER \\
\hline & Apr 1995 - Jun 2011 & 35 days & & CMOD5.n & UWI & $25 \mathrm{~km}^{2}$ & ESA \\
\hline QuikSCAT & Jul 1999 - Nov 2009 & 4 days & $\begin{array}{c}\text { Ku-band } \\
(13.4 \mathrm{GHz} \text {, } \\
2.2 \mathrm{~cm})\end{array}$ & KU_Model & V2 & $25 \mathrm{~km}^{2}$ & JPL \\
\hline ASCAT & Oct 2006 - Present & 29 days & $\begin{array}{c}\text { C-band } \\
(5.3 \mathrm{GHz}, \\
5.7 \mathrm{~cm})\end{array}$ & CMOD5.n & V1 & $25 \mathrm{~km}^{2}$ & EUMETSAT \\
\hline
\end{tabular}

2

3

4 
Table 2: Statistical comparison results of collocated $10 \mathrm{~m}$ wind speeds and direction from NDBC buoys and scatterometer ERS-1, ERS-2, QSCAT, and ASCAT products. Bias is defined as mean difference between buoy and scatterometer winds (in this order). Std, bs, $\rho$, and $\rho^{2}$ indicate standard deviation, regression symmetrical coefficient, scalar correlation coefficient, and vector correlation coefficient. The latter varies between -2 and +2 .

\begin{tabular}{|c|c|c|c|c||c|c|c|}
\cline { 2 - 8 } \multicolumn{1}{c|}{} & \multicolumn{4}{c||}{ Wind Speed } & \multicolumn{3}{c|}{ Wind Direction } \\
\cline { 2 - 8 } \multicolumn{1}{c|}{} & $\begin{array}{c}\text { Bias } \\
(\mathrm{m} / \mathrm{s})\end{array}$ & $\begin{array}{c}\text { STD } \\
(\mathrm{m} / \mathrm{s})\end{array}$ & bs & $\rho$ & $\begin{array}{c}\text { Bias } \\
(\mathrm{deg})\end{array}$ & $\begin{array}{c}\text { STD } \\
(\mathrm{deg})\end{array}$ & $\rho^{2}$ \\
\hline ERS-1 WNF & $\begin{array}{c}0.42 \\
(-0.06)\end{array}$ & $\begin{array}{c}1.36 \\
(1.10)\end{array}$ & $\begin{array}{c}1.02 \\
(1.00)\end{array}$ & $\begin{array}{c}0.92 \\
(0.94)\end{array}$ & -4 & 19 & 1.84 \\
\hline ERS-2 WNF & $\begin{array}{c}0.70 \\
(-0.15)\end{array}$ & $\begin{array}{c}1.41 \\
(1.09)\end{array}$ & $\begin{array}{c}1.01 \\
(1.02)\end{array}$ & $\begin{array}{c}0.93 \\
(0.95)\end{array}$ & -5 & 18 & 1.86 \\
\hline ERS-2 UWI & 0.13 & 1.31 & 0.99 & 0.93 & -2 & 38 & 1.33 \\
\hline QSCAT & -0.01 & 1.21 & 0.99 & 0.94 & -4 & 21 & 1.85 \\
\hline ASCAT & $\begin{array}{c}0.15 \\
(0.10)\end{array}$ & $\begin{array}{c}1.21 \\
(1.26)\end{array}$ & $\begin{array}{c}1.00 \\
(1.01)\end{array}$ & $\begin{array}{c}0.94 \\
(0.94)\end{array}$ & 0 & 18 & 1.90 \\
\hline
\end{tabular}

Table 3: Statistical comparison results of collocated $10 \mathrm{~m}$ wind speeds and direction from Tropical (TAO, PIRATA, RAMA) buoys and scatterometer ERS-1, ERS-2, QSCAT, and ASCAT products. Bias is defined as mean difference between buoy and scatterometer winds (in this order). Std, bs, $\rho$, and $\rho^{2}$ indicate standard deviation, regression symmetrical coefficient, scalar correlation coefficient, and vector correlation coefficient. The latter varies between -2 and +2 .

\begin{tabular}{|c|c|c|c|c||c|c|c|}
\cline { 2 - 7 } \multicolumn{1}{c|}{} & \multicolumn{4}{c||}{ Wind Speed } & \multicolumn{3}{c|}{ Wind Direction } \\
\cline { 2 - 8 } \multicolumn{1}{c|}{} & $\begin{array}{c}\text { Bias } \\
(\mathrm{m} / \mathrm{s})\end{array}$ & $\begin{array}{c}\text { STD } \\
(\mathrm{m} / \mathrm{s})\end{array}$ & bs & $\rho$ & $\begin{array}{c}\text { Bias } \\
(\mathrm{deg})\end{array}$ & $\begin{array}{c}\text { STD } \\
(\mathrm{deg})\end{array}$ & $\rho^{2}$ \\
\hline ERS-1 WNF & $\begin{array}{c}0.77 \\
(0.26)\end{array}$ & $\begin{array}{c}1.23 \\
(0.99)\end{array}$ & $\begin{array}{c}0.99 \\
(0.95)\end{array}$ & $\begin{array}{c}0.90 \\
(0.91)\end{array}$ & -9 & 19 & 1.64 \\
\hline ERS-2 WNF & $\begin{array}{c}0.88 \\
(0.12)\end{array}$ & $\begin{array}{c}1.32 \\
(0.91)\end{array}$ & $\begin{array}{c}1.01 \\
(0.99)\end{array}$ & $\begin{array}{c}0.90 \\
(0.92)\end{array}$ & -10 & 20 & 1.68 \\
\hline ERS-2 UWI & 0.46 & 1.12 & 0.95 & 0.90 & 0 & 31 & 1.24 \\
\hline QSCAT & 0.19 & 0.95 & 0.96 & 0.91 & 1 & 16 & 1.74 \\
\hline ASCAT & $\begin{array}{c}0.45 \\
(0.32)\end{array}$ & $\begin{array}{c}1.02 \\
(1.01)\end{array}$ & $\begin{array}{c}0.95 \\
(0.94)\end{array}$ & $\begin{array}{c}0.91 \\
(0.90)\end{array}$ & -3 & 15 & 1.78 \\
\hline
\end{tabular}




\section{Figures}

2 Figure 1: C-band model power coefficient $\mathrm{A}_{0}$ from observed scatterometer backscatter coefficients (eq. 2) versus its predicted values from Cmod5.n GMF and collocated buoy winds. Red, blue, and green colors dots indicate $A_{0}$ values associated to inner- (mid beam $\theta$ of $\left.18^{\circ}\right)$, middle- $\left(\theta\right.$ of $\left.27^{\circ}\right)$, and outer- $\left(\theta\right.$ of $\left.45^{\circ}\right)$ swaths, respectively.

Figure 2: Differences between expected and measured backscatter (uncorrected - dashed, corrected - solid) coefficients as a function of the incidence angle.

Figure 3: Mean Differences between ERS-2 UWI and ERS-2 WNF backscatter coefficients (uncorrected - dashed, corrected - solid) as a function of the incidence angle. Figure 4: Time series of monthly differences between NDBC buoy and scatterometer wind speeds. Full and dashed lines indicate running bias and bias \pm STD, respectively.

Figure 5: Time series of monthly differences between Tropical (TAO, PIRATA, RAMA) buoy and scatterometer wind speeds. Full and dashed lines indicate bias and bias \pm STD, respectively.

15 Figure 6: Annual mean scatterometer wind speeds ( 1 st column), mean ( $2^{\text {nd }}$ column) and STD $\left(3^{\text {rd }}\right.$ column) differences (CFSR minus scatterometer). First, second, third, and fourth rows show statistics for ERS-1/N, ERS-2/N, QuikSCAT, and ASCAT/N, respectively.

Figure7: Annual mean scatterometer wind speeds ( 1 st column), bias ( $2^{\text {nd }}$ column), and STD ( $3^{\text {rd }}$ column) differences ERA Interim minus scatterometer wind speeds. First, second, third, and fourth rows are related to statistics estimated for ERS-1/N, ERS-2/N, QuikSCAT, and ASCAT/N, respectively.

Figure 8: Annual mean wind speed estimated from available monthly averaged collocated scatterometer (ERS-1/N, ERS-2/N, QSCAT, ASCAT/N) and CFSR data. They are calculated for the period March $1992-$ March 2011, and for latitudinal oceanic zones: a) $50^{\circ} \mathrm{N}-70^{\circ} \mathrm{N}$; b) $20^{\circ} \mathrm{N}-40^{\circ} \mathrm{N}$; c) $10^{\circ} \mathrm{S}-10^{\circ} \mathrm{N}$; d) $40^{\circ} \mathrm{S}-20^{\circ} \mathrm{S}$; and e) $70^{\circ} \mathrm{S}-50^{\circ} \mathrm{S}$. CFSR_Scatt (thin black line) indicate CFSR data collocated with scatterometer retrievals, whereas CFSR (dashed black line) indicates annual winds calculated from all CFSR data.

Figure 9: Annual mean speed estimated from available monthly averaged collocated scatterometer (ERS-1/N, ERS-2/N, QSCAT, ASCAT/N) and ERA Interim data. They are calculated for the period March 1992 - March 2011, and for latitudinal oceanic zones: a) $50^{\circ} \mathrm{N}-70^{\circ} \mathrm{N}$; b) $20^{\circ} \mathrm{N}-40^{\circ} \mathrm{N}$; c) $10^{\circ} \mathrm{S}-10^{\circ} \mathrm{N}$; d) $40^{\circ} \mathrm{S}-20^{\circ} \mathrm{S}$; and e) $70^{\circ} \mathrm{S}-50^{\circ} \mathrm{S}$. ERAI_Scatt (thin black line) indicate ERA Interim data collocated with scatterometer retrievals, whereas ERAI (dashed black line) indicates annual winds calculated from 6-hourly analyses.

Figure 10: Time series of monthly-averaged wind speeds estimated from collocated scatterometer (ERS-1/N, ERS-2/N, QSCAT, ASCAT/N) and CFSR data. They are shown for five locations which coordinates are indicated in the top/leftcorner of each panel.

Figure 11: Time series of monthly-averaged wind speeds estimated from collocated scatterometer (ERS-1/N, ERS-2/N, QSCAT, ASCAT/N) and ERA Interim data. They are shown at five locations which latitudes and longitudes are indicated at top/left of each panel. 

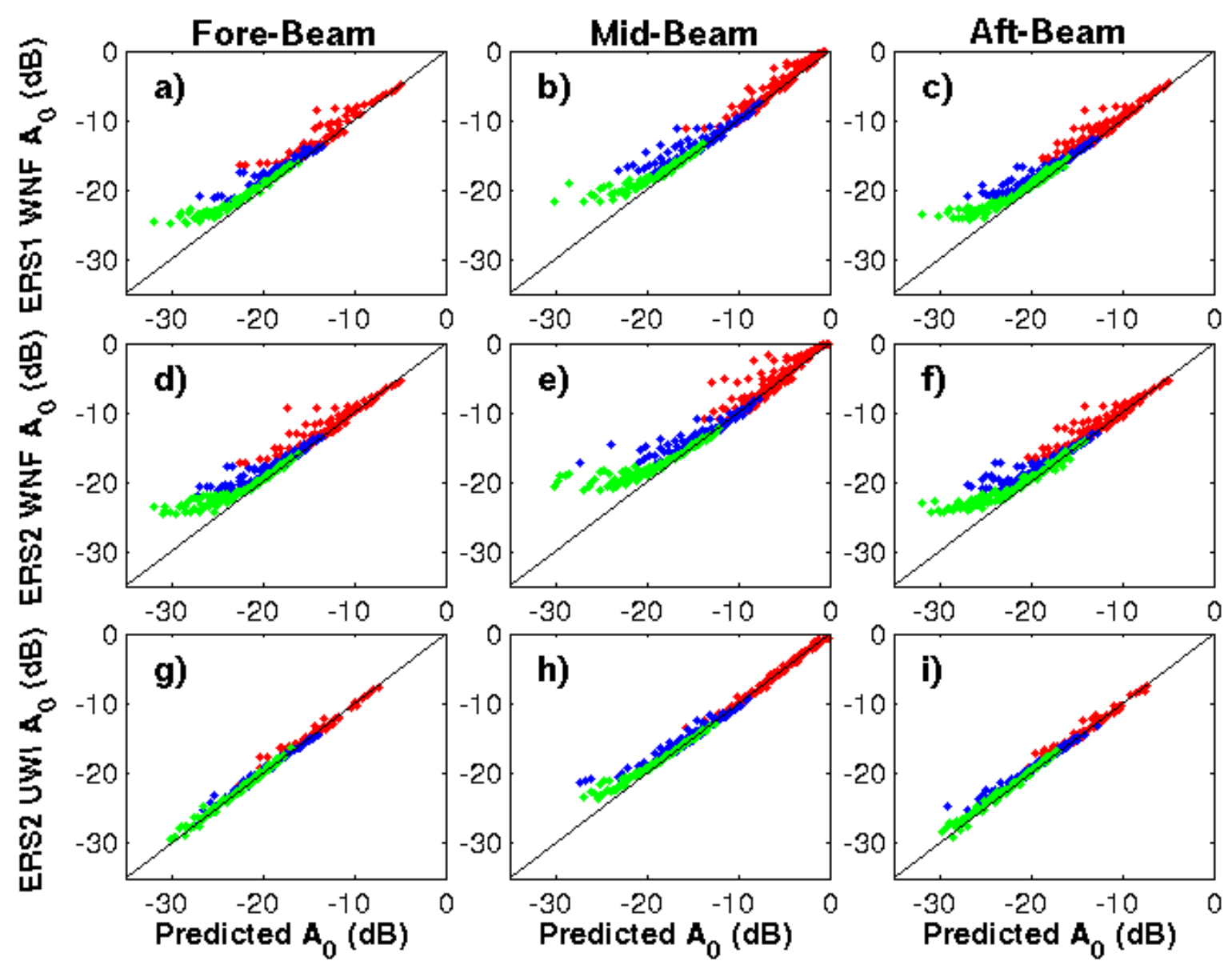

16 Figure 1: C-band model power coefficient $\mathrm{A}_{0}$ from observed scatterometer backscatter coefficients (eq. 2) versus its predicted values from Cmod5.n GMF and collocated buoy winds. middle- $\left(\theta\right.$ of $\left.27^{\circ}\right)$, and outer- $\left(\theta\right.$ of $\left.45^{\circ}\right)$ swaths, respectively. 

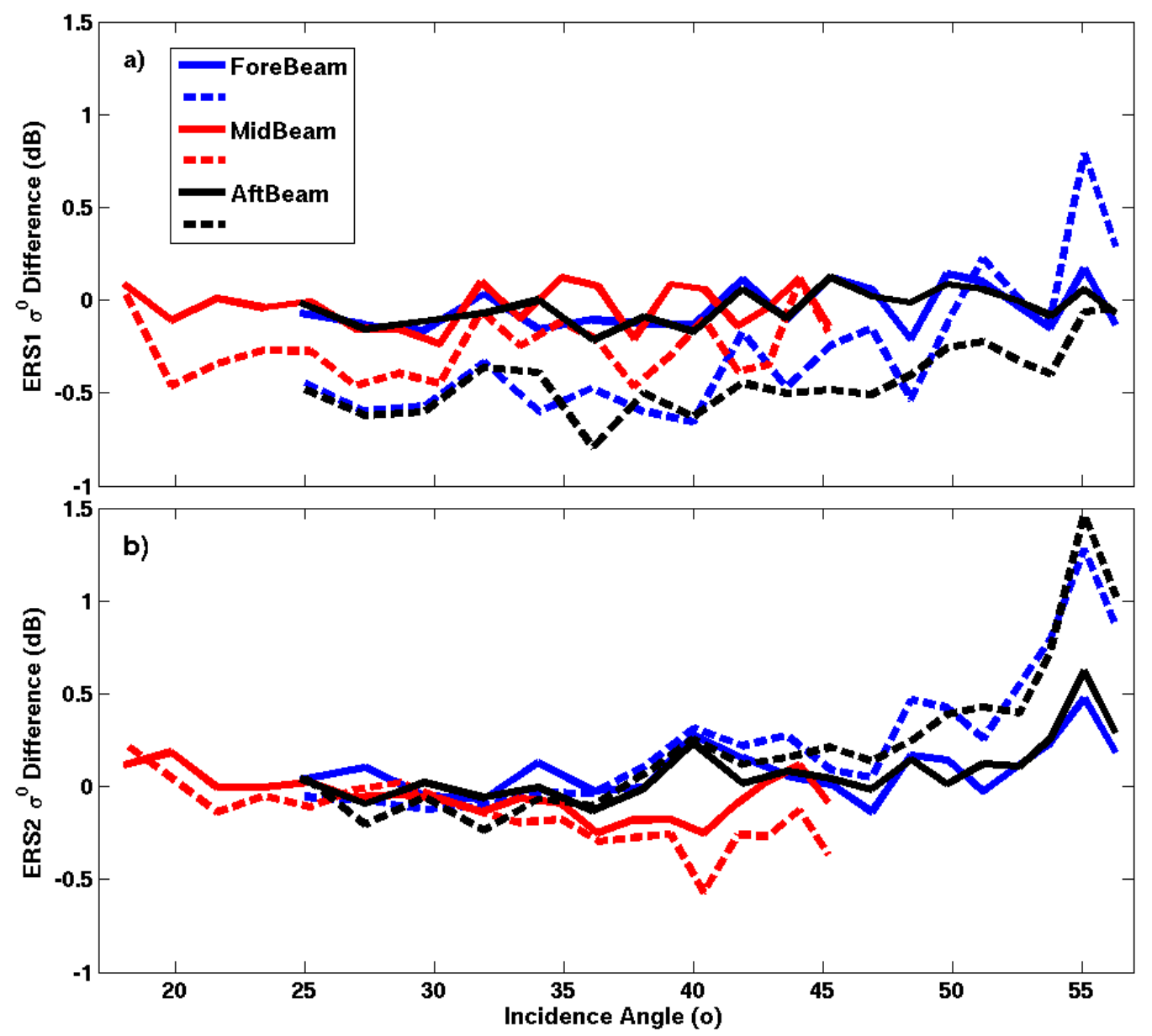

19

Figure 2: Differences between expected and measured backscatter (uncorrected - dashed, corrected - solid) coefficients as a function of the incidence angle. 


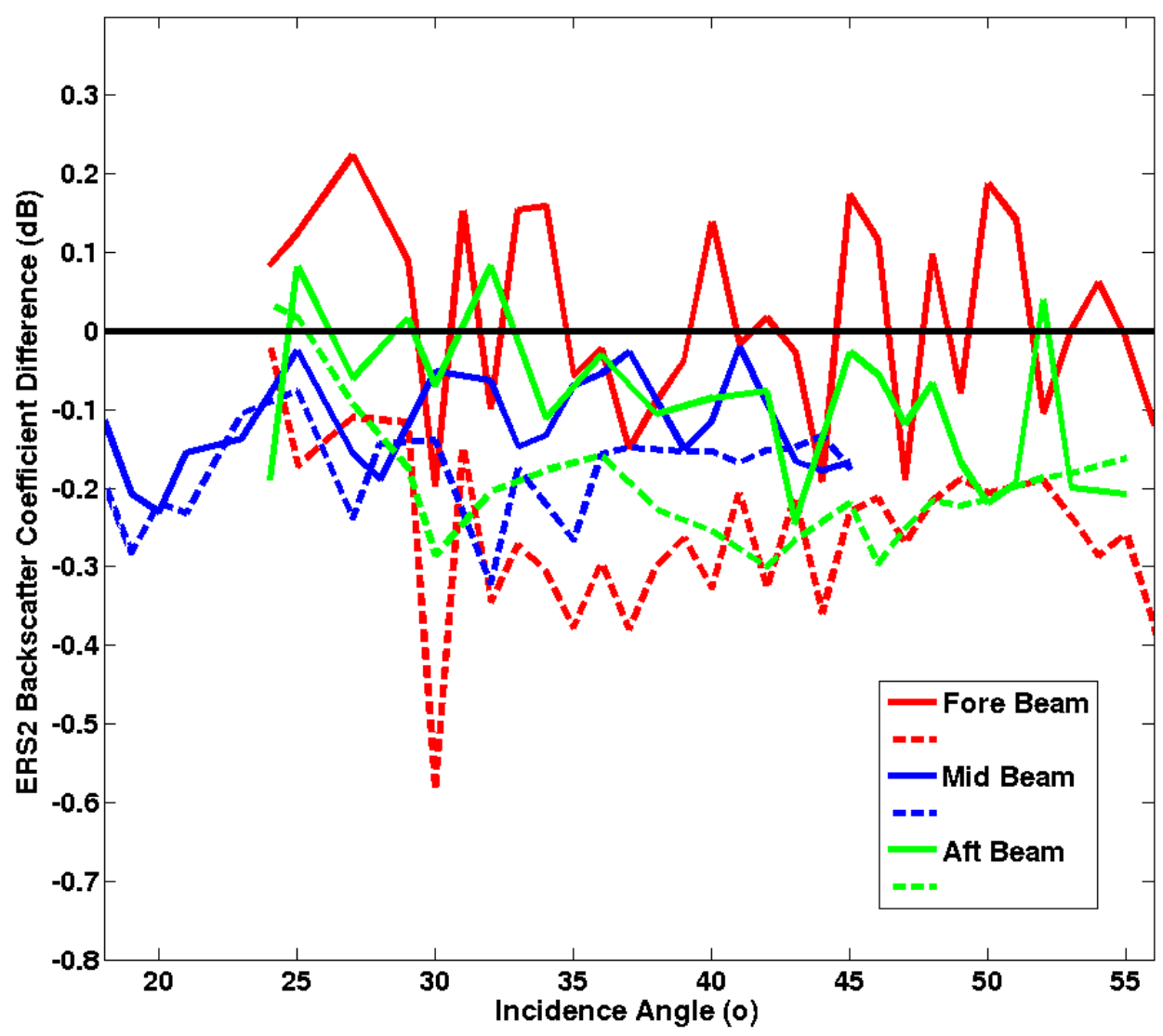

Figure 3: Mean Differences between ERS-2 UWI and ERS-2 WNF backscatter coefficients (uncorrected - dashed, corrected - solid) as a function of the incidence angle. 


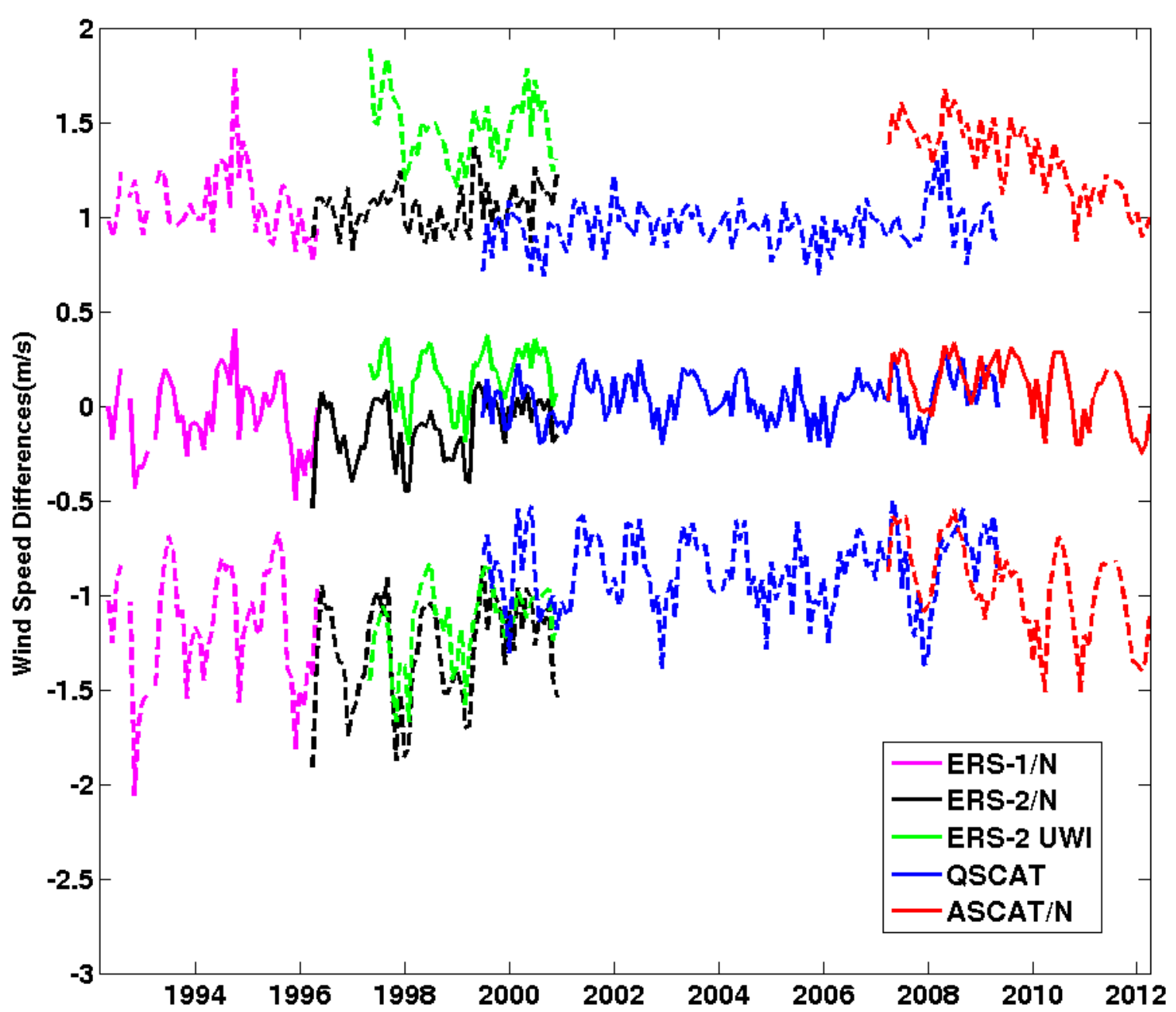

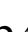

Figure 4: Time series of monthly differences between NDBC buoy and scatterometer wind speeds. Full and dashed lines indicate running bias and bias \pm STD, respectively. 


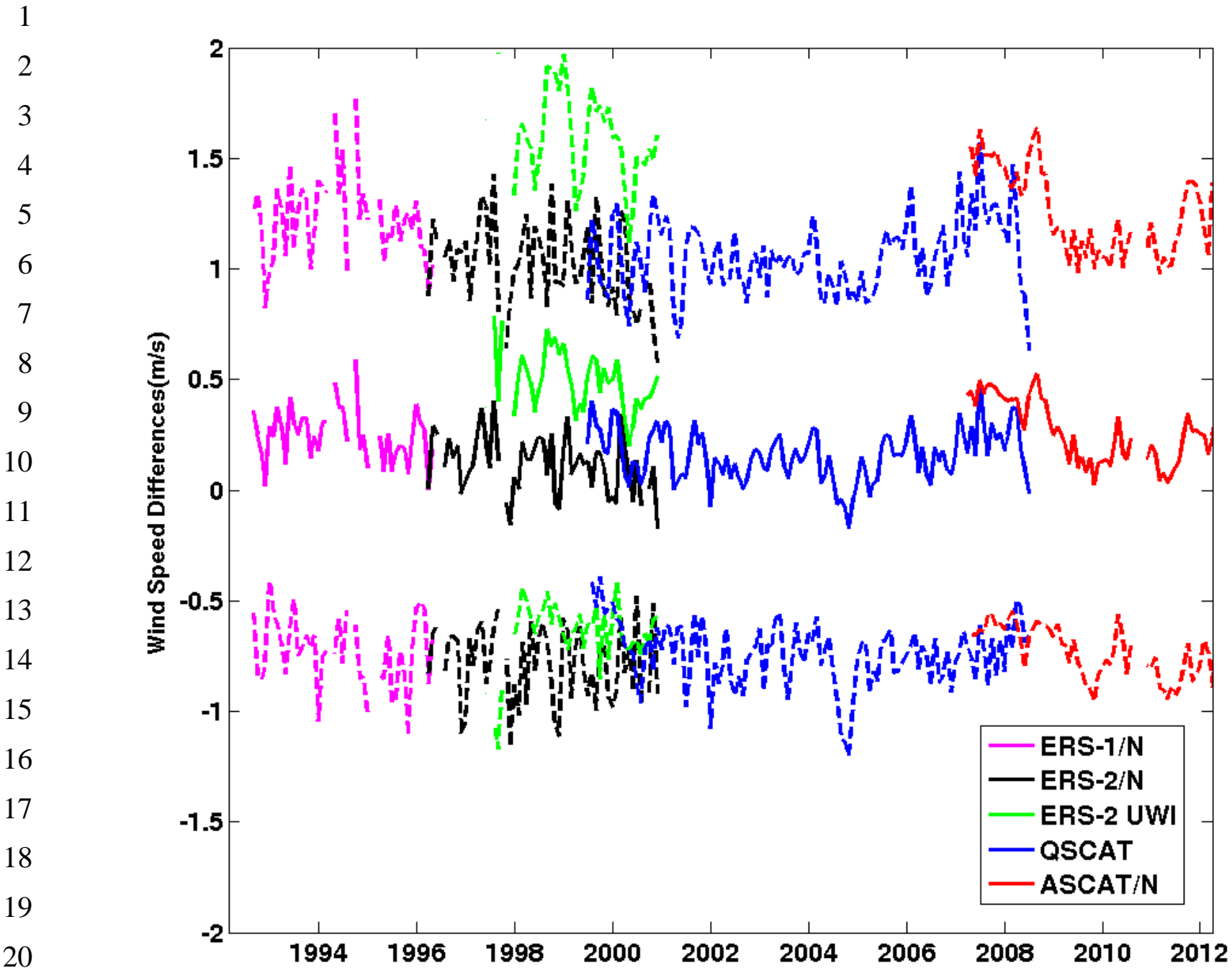

Figure 5: Time series of monthly differences between Tropical (TAO, PIRATA, RAMA) buoy and scatterometer wind speeds. Full and dashed lines indicate bias and bias \pm STD, respectively. 

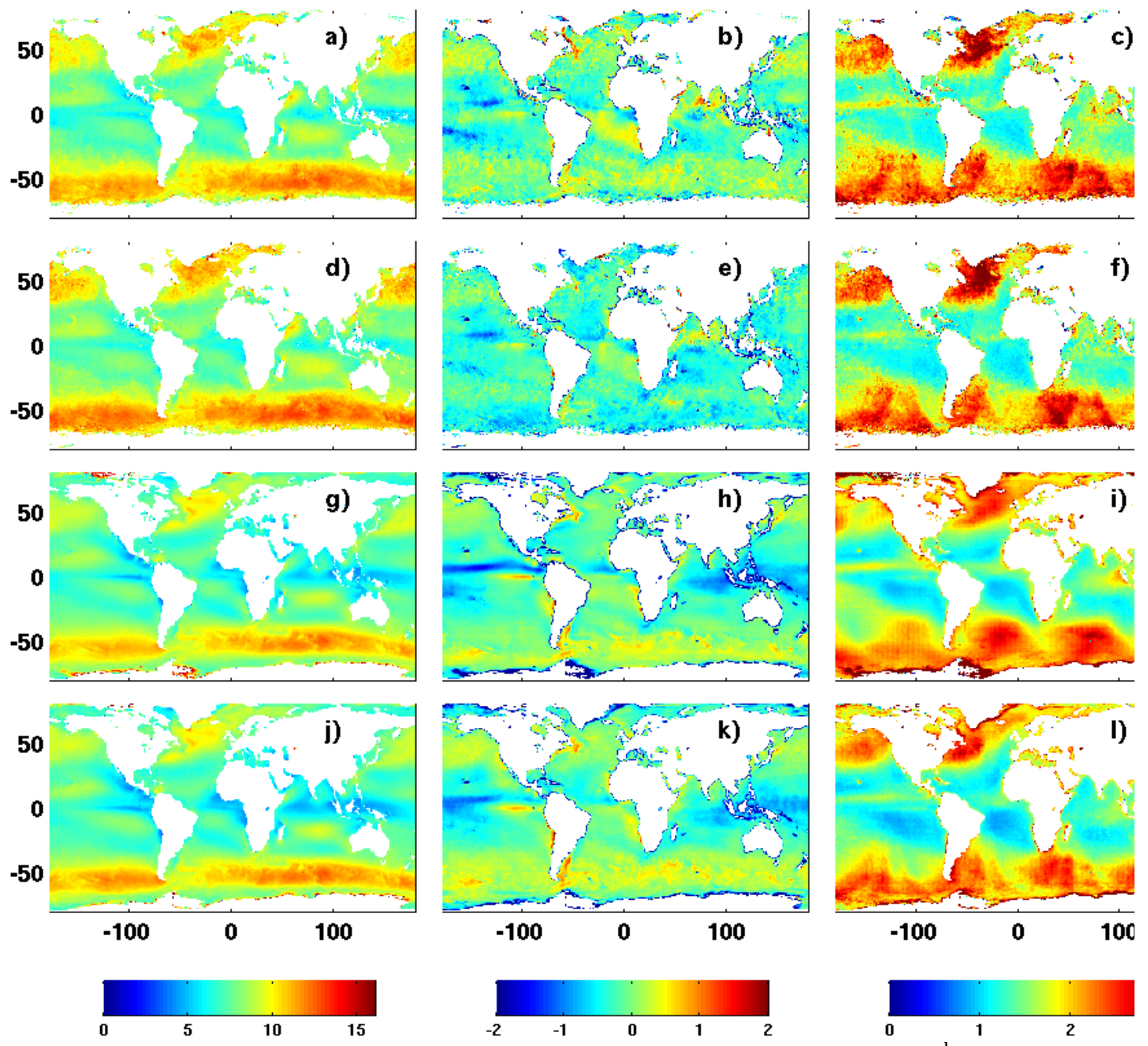
Figure 6: Annual mean scatterometer wind speeds ( 1 st column $)$, mean $\left(2^{\text {nd }}\right.$ column $)$ and
STD ( $3^{\text {rd }}$ column) differences (CFSR minus scatterometer). First, second, third, and fourth rows show statistics for ERS-1/N, ERS-2/N, QuikSCAT, and ASCAT/N, respectively. 

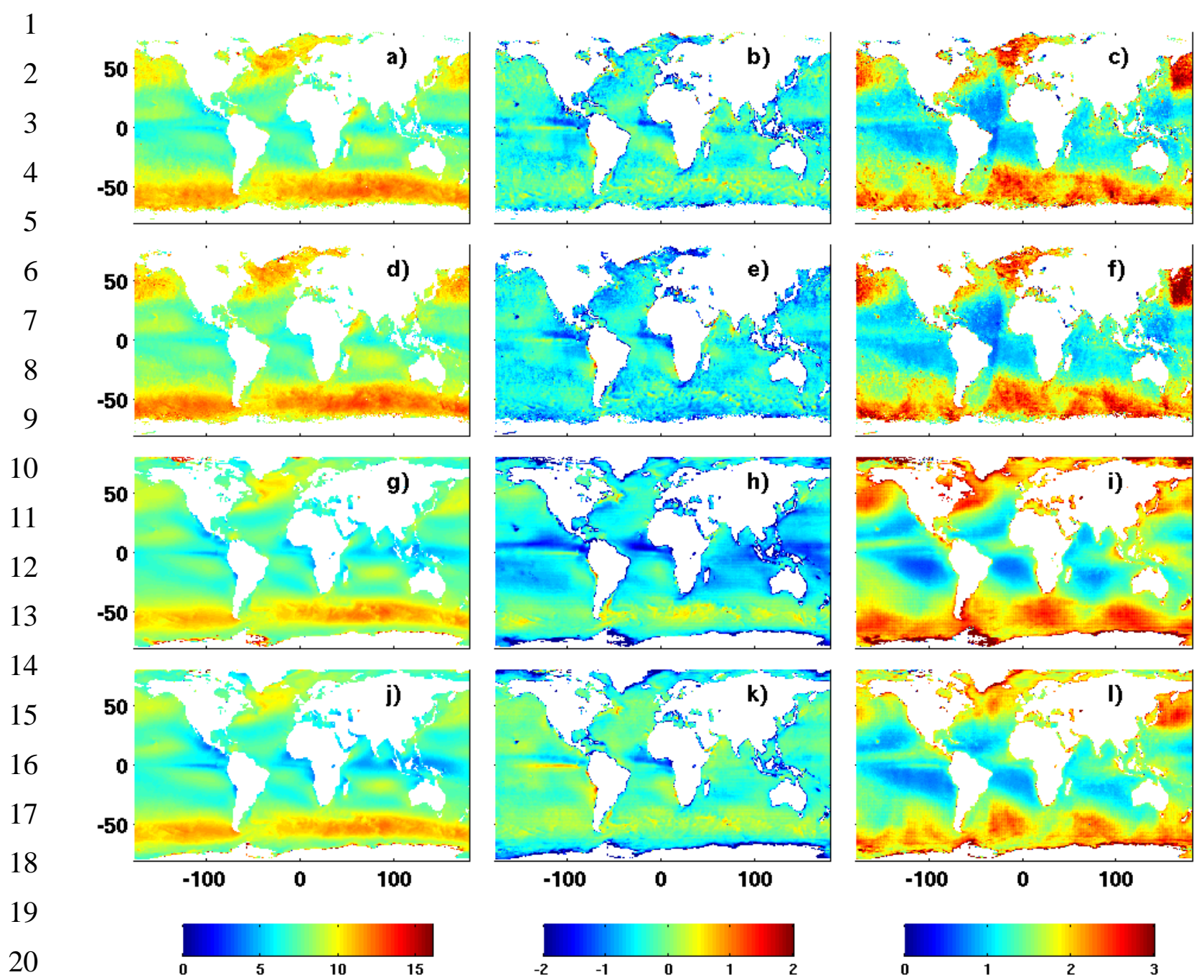

21 Figure 7: Annual mean scatterometer wind speeds ( 1 st column), bias ( $2^{\text {nd }}$ column), and STD $\left(3^{\text {rd }}\right.$ column) differences ERA Interim minus scatterometer wind speeds. First, second, third, and fourth rows are related to statistics estimated for ERS-1/N, ERS-2/N, QuikSCAT, and ASCAT/N, respectively. 

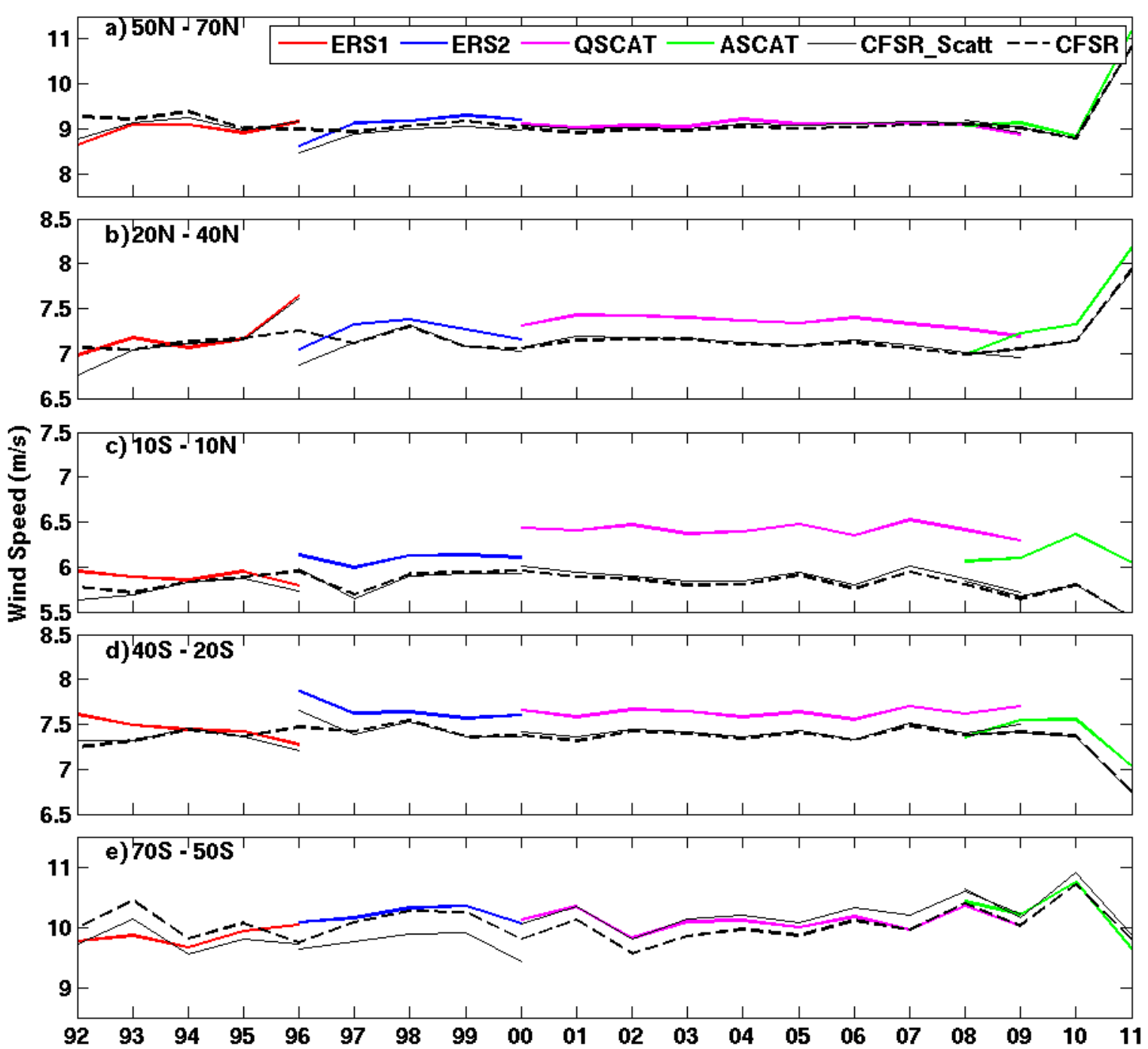

Figure 8: Annual mean wind speed estimated from available monthly averaged collocated scatterometer (ERS-1/N, ERS-2/N, QSCAT, ASCAT/N) and CFSR data. They are calculated for the period March 1992 - March 2011, and for latitudinal oceanic zones: a) $50^{\circ} \mathrm{N}-70^{\circ} \mathrm{N}$; b) $20^{\circ} \mathrm{N}-40^{\circ} \mathrm{N}$; c) $10^{\circ} \mathrm{S}-10^{\circ} \mathrm{N}$; d) $40^{\circ} \mathrm{S}-20^{\circ} \mathrm{S}$; and e) $70^{\circ} \mathrm{S}-50^{\circ} \mathrm{S}$. CFSR_Scatt (thin black line) indicate CFSR data collocated with scatterometer retrievals, whereas CFSR (dashed black line) indicates annual winds calculated from all CFSR data. 

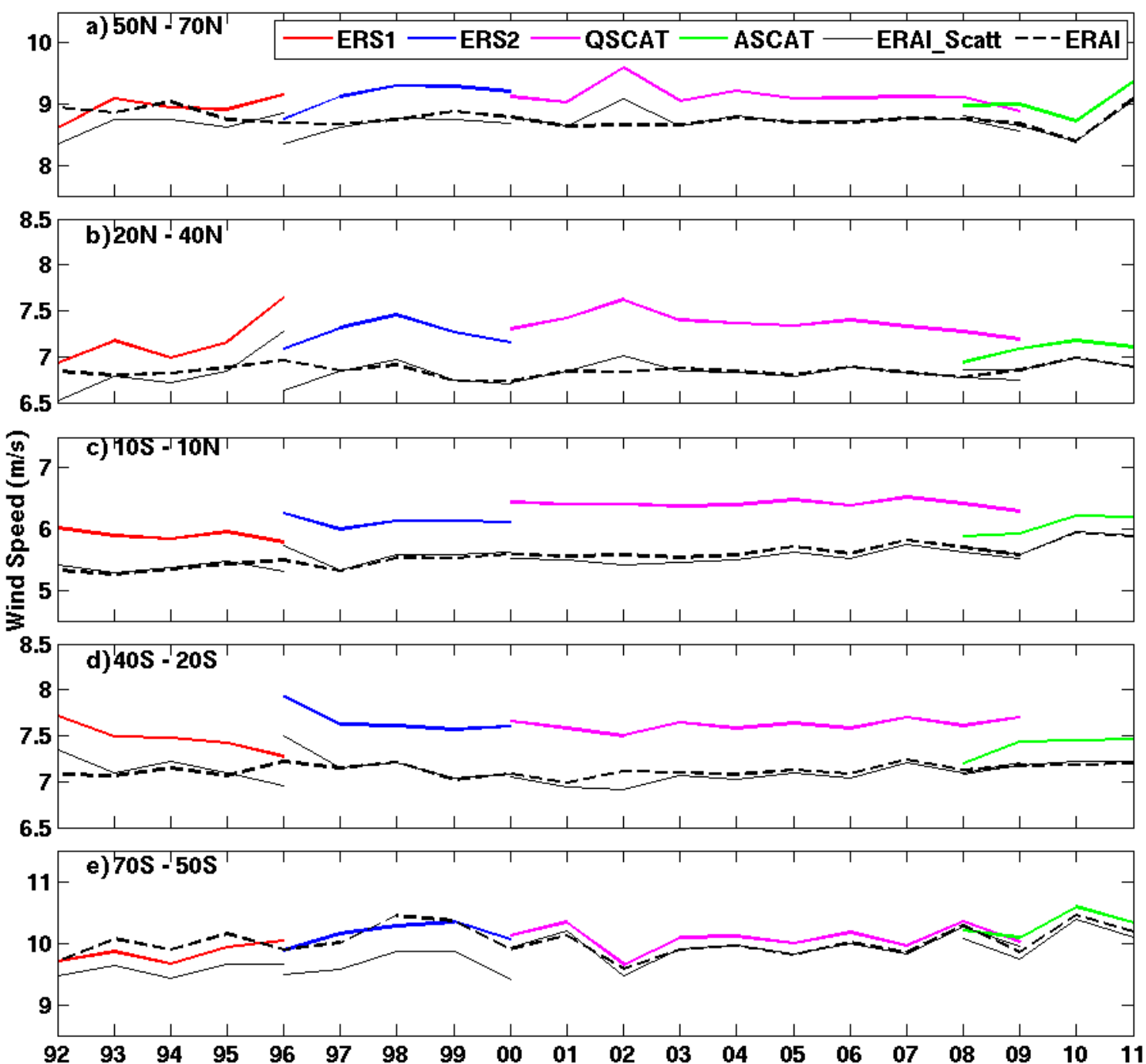

Figure 9: Annual mean speed estimated from available monthly averaged collocated scatterometer (ERS-1/N, ERS-2/N, QSCAT, ASCAT/N) and ERA Interim data. They are calculated for the period March 1992 - March 2011, and for latitudinal oceanic zones: a) $50^{\circ} \mathrm{N}-70^{\circ} \mathrm{N}$; b) $20^{\circ} \mathrm{N}-40^{\circ} \mathrm{N}$; c) $10^{\circ} \mathrm{S}-10^{\circ} \mathrm{N}$; d) $40^{\circ} \mathrm{S}-20^{\circ} \mathrm{S}$; and e) $70^{\circ} \mathrm{S}-50^{\circ} \mathrm{S}$. ERAI_Scatt (thin black line) indicate ERA Interim data collocated with scatterometer retrievals, whereas ERAI (dashed black line) indicates annual winds calculated from 6hourly analyses. 

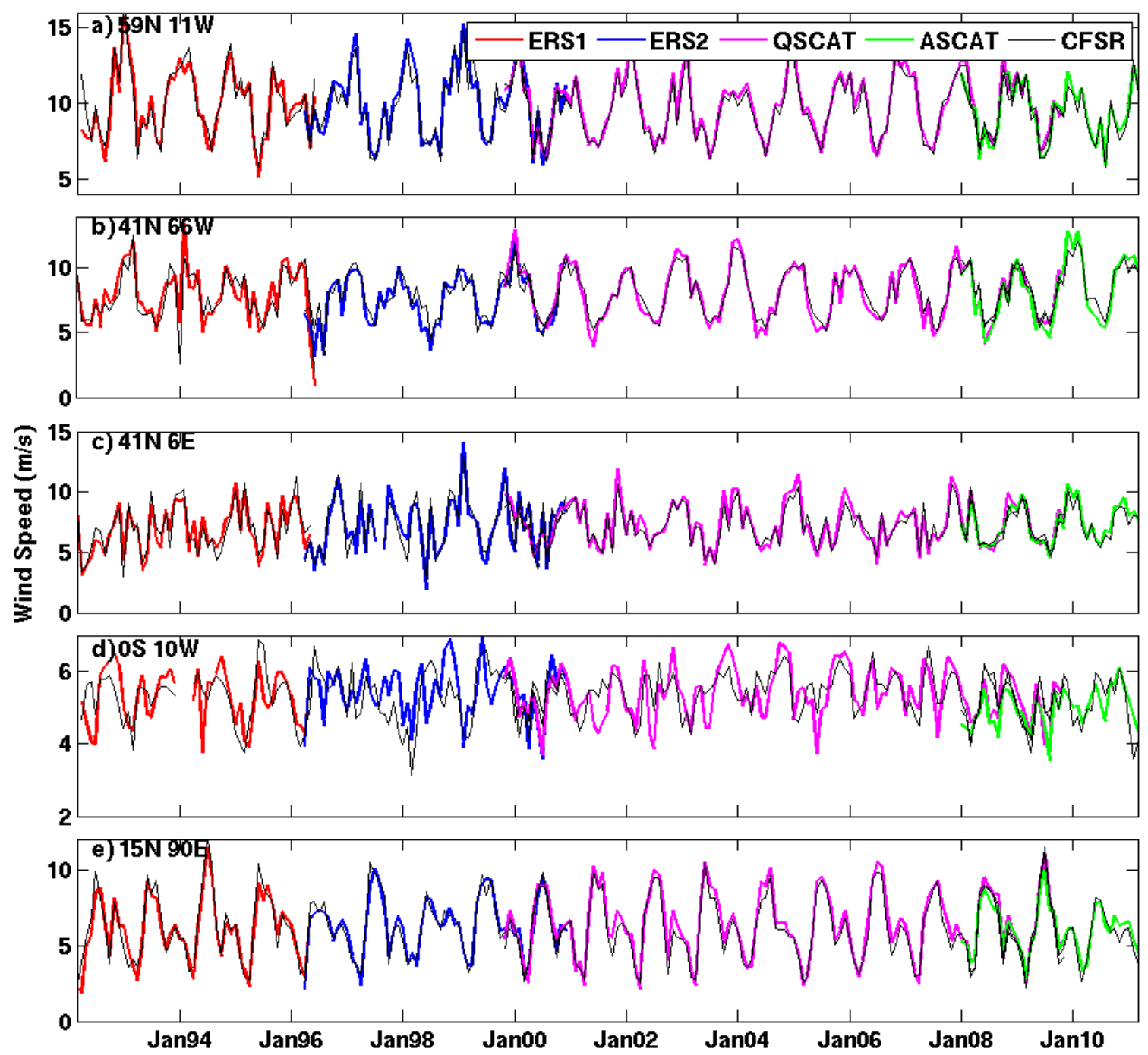

Figure 10: Time series of monthly-averaged wind speeds estimated from collocated scatterometer (ERS-1/N, ERS-2/N, QSCAT, ASCAT/N) and CFSR data. They are shown for five locations which coordinates are indicated in the top/leftcorner of each panel. 

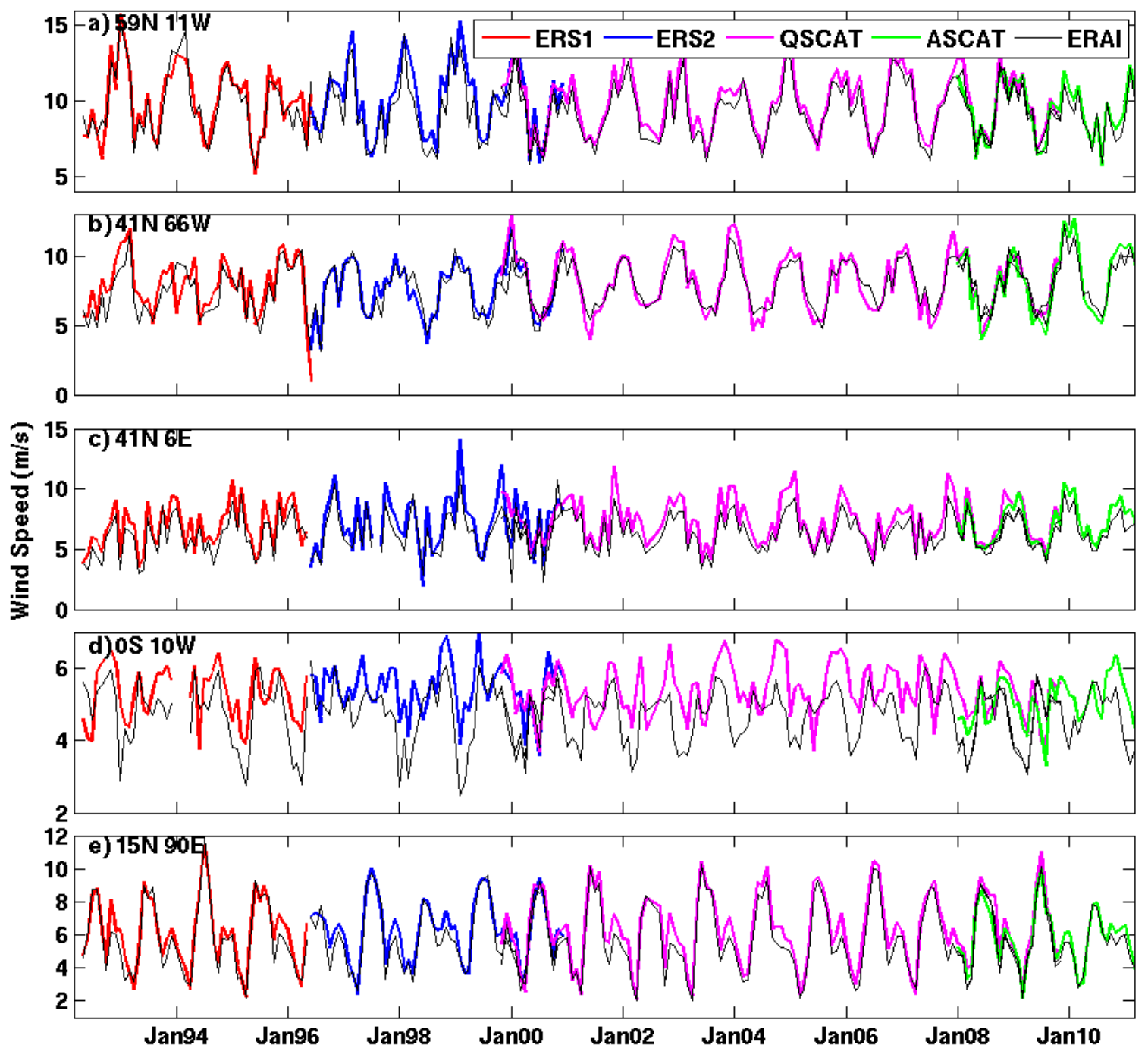

Figure 11: Time series of monthly-averaged wind speeds estimated from collocated scatterometer (ERS-1/N, ERS-2/N, QSCAT, ASCAT/N) and ERA Interim data. They are shown at five locations which latitudes and longitudes are indicated at top/left of each panel. 